\title{
EN LA SUBSTANCIA NO HAY ORDEN. DEFINICIÓN Y DIFERENCIA EN LA FILOSOFÍA DE ARISTÓTELES
}

\author{
Serafín VEGAS GONZÁLEZ \\ Universidad de Alcald
}

Uno de los lugares comunes más profundamente enraizados a lo largo de toda la historia del pensamiento es el de que la filosofía hace de lo racional la cuestión por excelencia al tratar de revelar lo originario de las experiencias humanas del mundo, poniendo aquella originariedad en función de la unidad del ser de la realidad y haciendo de esta unidad el modelo de la explicación filosófica entendida como pensamiento del ser. Lo originario y lo filosófico se entrecruzan, pues, justamente en la medida en que la razón filosófica se constituye a sí misma como manifestación de la unidad de lo racional y de lo en sí frente a las plurales y diferenciadas estipulaciones de la apariencia ${ }^{1}$. Aquel tan repetido planteamiento tradicional ha de ser, sin embargo, tomado con las debidas precauciones y merece ser precisado en función de los requisitos exigibles a la historiación de lo filosófico.

1 Esta caracterización de lo filosófico sigue persistiendo con fuerza en nuestros días. Muestra de ello puede ser la apelación a la unidad, en la que Habermas hace reposar la esencia de lo filosófico: "La filosofia se esfuerza desde sus comienzos por explicar según principios el mundo como conjunto, la unidad en la multiplicidad de las apariencias; principios que se encuentran en la razón, y no en la comunicación con una divinidad más allá del mundo, ni siquiera estrictamente en el recurso al fundamento de un cosmos que abarcase naturaleza y sociedad. El pensamiento griego no apunta ni a la teología ni a una cosmología ética, en el sentido de las grandes religiones cósmicas. Si hay algo común a las doctrinas filosóficas, es la intención de pensar el ser o la unidad del mundo por la vía de una explicación de las experiencias de la razón en el trato consigo mismaw: Theorie des kommunikativen Handelns, I (Frankfurt a. M., Suhrkamp Verlag, 1981), p. 15 (hay trad. cast.). Incluso las propuestas que, en nuestro tiempo, abogan por una cultura posfilosófica lo hacen a partir del supuesto de que el pensamiento filosófico ha estado siempre supeditado a los postulados de un ordenamiento racional uno y unitario, en el que, en última instancia, quedaban ocultos los derechos y exigencias de la pluralidad diferenciada de lo real. 
De acuerdo con tales requisitos, resulta ser bien cierto que la filosofía nació, en palabras de Heráclito, como un "escuchar al logos" en el que habría de presenciarse el ser (la presencia) de lo existente (lo presente) en la unidad «única y común" que rige (arche) "todo por medio de todo", en cuyo des-velarse (aletheie) se hace presente y se oculta, a la vez, la realidad (la physis, "que ama/gusta ocultarse"), es decir, la armonía originaria del "ser todo uno", "lo común" (to xynon) en lo que lo plural y lo diferenciado son uno. Planteadas así las cosas, los filósofos serían los encargados de poner de manifiesto aquella «armonía tensa de contrarios diferenciados", que es la presencia auténtica, el ser (logos, physis, arche, aletheie, to xynon) que resulta incomprensible a los que se limitan a lo que aparece, lo presente-diferenciado. Estos, por contraste con los filósofos, son los "ignorantes» o axynetoi, los que no escuchan la voz del logos y de lo to xynon ("lo común») y, por ello, no re-ligan o unen (xyniasin) lo diferente-variado (diapheromenon) de lo presente-apare (cie)nte, que, sin embargo, concuerda consigo mismo (eauto sympheretai) en la presencia/unidad originaria.

El conocimiento de los «ignorantes» (de los «incapaces de unir", axynetoi) resulta ser, por ello, para Heráclito un conocimiento diferenciador que busca la de-terminación (poner termini diferenciados), de-limitando (estableciendo limitem) y de-finiendo (acudiendo a fines, es decir, fronteras/límites) a algo en y por su separación/oposición a lo que no aparece como perteneciendo al marco de lo determinado, delimitado y definido en las donaciones del conocimiento de los "hombres ordinarios", que en Heráclito se confunden con los «ignorantes". Frente a ello, el saber filosófico queda configurado plenamente en Heráclito (y en Parménides) ${ }^{2}$ como ajeno a lo de-limitado y de-terminado (es decir, lo que es propio de lo peras), explicitando así lo que había sido el supuesto básico de los iniciadores de la filosofía occidental, a saber, que la presencia/ser (physis, arche) nada tiene que ver con el límite diferenciador (peras): es lo a-peiron, el acuerdo y re-conocimiento, que "remonta la discordia" en lo Mismo de lo que aparece (y, por ello, desaparece) ${ }^{3}$.

2 Aun teniendo en cuenta que, en los textos de Parménides, la vía de lo que aparece (la vía de la opinión) tiene una mayor consistencia que en Heráclito, algo que nos limitamos a dejar meramente apuntado.

3 Estamos, claro está, haciendo referencia a la sentencia atribuida a ANAXIMANDRO (arche ton onton to apeiron), vista a la luz de la traducción heideggeriana de la segunda parte de los Grundbegriffe (Frankfurt a. M., Vittorio Klostermann, 1981) (hay trad. cast.): "Para lo en cada caso presente, la disposición es la acción de impedir que haya limitess (subray. nuestro). Ello ha de ser puesto en relación con lo que se dice en el texto de ANAXIMANDro (DK 12 A 9), el primero 
Si la historia del logos presocrático aparece, por lo general, dominada por la negación de la de-finición y de la de-limitación, por ser éstas incompatibles con la radical unidad originaria que con-forma el ser de todo lo presente, la situación se tornará harto distinta cuando la filosofía de Sócrates plantee la necesidad de que fuera justamente la definición el elemento prioritario del discurso filosófico 4. Sócrates, en efecto y al decir de Aristóteles (Met. I, 6, 987b3-4) fue "el primero capaz de pensar acerca de las definiciones", proponiendo al quehacer filosófico unas tareas que habrían de discurrir por sendas muy alejadas de las que hasta entonces habían transitado los filósofos presocráticos, los cuales, aunque ya "habían comenzado a hablar y a definir (horitsesthai) acerca de la esencia (peri tou ti estin), procedieron de manera demasiado simple; definían (horitsonto), en efecto, superficialmenten: Met. I, 6, 987b20-22. A ello, por lo demás, no iba a hacer oídos sordos el Platón maduro, para el cual (según Thaet., 206c y ss.) el logos, entendido como "manifestación del propio pensamiento por medio del sonido, articulado en verbos y nombres" adquiere consistencia al convertirse en búsqueda de la definición científica, que muestra el objeto "a través de sus elementos con la ayuda de la recta opinión" y, también, lo diferencia de todos los demás objetos, de tal modo que «si captas la diferencia característica de un objeto, captas también su logosn (Thaet, 208d). A partir de aquí, el Sofista platónico iba a esbozar los primeros pasos de un logos definidor que habría de hacerse manifiesto como división de géneros que estructuran la presencia misma (el ser) de las ideas (eide). De haber recorrido este camino hasta el final, la filosofia platónica se hubiera visto llevada a abrir de par en par las puertas del ejercicio de lo logico, pero ello habría resultado ser incompatible con el supuesto operativo del pensamiento platónico, el de la preeminencia absoluta de lo ontológico, que remite a la presencia del eidos (del Ser y de lo Uno, en definitiva) como lo que es por excelencia, frente a las plurales manifestaciones, meramente participadas, de lo que hace referencia a la división/definición de las cosas cuyo significado ofrece el logos-lenguaje.

de los fragmentos filosóficos conservados, y que HEIDEGGER traduce (op. cit., p. 94): «Pues de donde y desde donde la proveniencia es para lo en cada caso presente, también la desaparición en esto (en tanto que en lo Mismo) proviene en correspondencia al estado de necesidad que obliga, esto es: da a todo lo presente mismo (a partir de sí) acuerdo y también evaluación (reconocimiento), deja que uno sea para el otro (todo esto) remontando la discordia en correspondencia a la asignación del dar tiempon.

4 Acerca del tema de la definición y su prioridad, tal como es planteado en la primitiva dialéctica platónica, nos hemos ocupado en Sócrates y el conocimiento. Ensayos sobre el Menón (Alcalá, Servicio de Publicaciones de la Universidad de Alcalá, 1993), pp. 62-86. 
La consistencia, por ello, del logos definidor platónico no había de verse como consistencia absoluta ni aquel logos definidor debía ser entendido como auténtico logos filosófico, "conocimiento y amor" del eidos que, siendo en y por sí mismo, es el ser mismo (physis, arche) y la razón (logos) a los que se remite lo apare(cie)nte de las cosas. Platón, por todo ello, no pudo llegar a una filosofía sistemática del pensamiento definidor/delimitador porque no alcanzó a desprenderse de los supuestos básicos que conformaron el nacimiento de la filosofía occidental. A pesar de ello, Platón atisbó la necesidad de un nuevo proceder filosófico que iba a encontrar acomodo y expresión en la teoría aristotélica del logos definidor, para el que la unidad del "ser en cuanto ser" se conjuga y se resuelve en la de-limitación y de-terminación de la ousia, del eidos, de la esencia ( $t i$ esti, to ti en einai) de-finida 5 . A partir de Aristóteles, la búsqueda filosófica de la racionalidad y del significado racional del discurso acerca de la realidad iban a modificar no poco decisivamente los planteamientos que hasta entonces había seguido el acontecer de lo filosófico, lo que obliga, de algún modo, a modificar aquel viejo tópico, al que nos referíamos al comenzar este trabajo, de que la filosofía ha consistido siempre en ser búsqueda de la unidad, sin más. Lo que de actual pueda seguir teniendo el pensamiento aristotélico acerca de la definición y de lo racional nos descubre, por el contrario, otras vertientes que pueden convertirse en fuente de fecundas reflexiones para el pensamiento de nuestro tiempo ${ }^{6}$.

\section{Aristóteles: filosofía y definición}

Hablando en líneas generales, la filosofía prearistototélica había hecho de la physis y del ser lo apeiron (lo carente de límite y determinación diferenciadora: pe-

5 Para la definición como donación de la ousia, cfr. An. Post. I, 4, 73a37. Que la definición es revelación del eidos aparece destacado en textos como Fis. II, 1, 193a31, mientras que, por ejemplo, An. Post. II, 3, 90b4 o ibid. II, 10, 93629 manifiestan que la definición es uenunciado/fórmula (logos) de lo ti estis, en paralelo con lo que dicen Top. I, 5, 101 b38 y Met. V, 6, 1016a33-34, a saber, que la definición «es el logos que significa lo to ti en einabi.

6 No es de extrafiar, por ello, la atención que determinadas parcelas del pensamiento analítico, tan preocupado por ofrecer un aceptable sentido del significado de lo racional, siguen prestando, directa o indirectamente, a la teoría aristotélica acerca del pensamiento definidor. Una muestra de ello puede verse en SoraBjI, R., "Aristotle and Oxford Philosophy", en American Philosophical Quarterly, 6, 1969, pp. 127-135, y en algunos de los trabajos, editados por J. H. FETZER, D. Shatz y N. SCHLESINGER, de Definitions and Definability: Philosophical Perspectives (Dordrecht/Boston/London, Kluwer Academic Publishers, 1991). Vid., igualmente, aunque desde orra perspectiva, OrTiz Hill, C., Rethinking Identity. On the Foundations of Analytic Philosophy (New Haven/London, Yale University Press, 1997). 
ras) y, por ello, el logos era visto como «el impedir que haya límites». Esta orientación se vio básicamente alterada cuando Aristóteles, creando la teoría lógica, fue capaz de armonizar las exigencias de la unidad que da sentido al pensar filosófico con la manifestación consistente y diferenciada de lo presente (de las cosas), haciendo del logos-definidor (el logos que pone límites) ${ }^{7}$ un eje básico no sólo de la doctrina lógica aristotélica ${ }^{8}$, sino también de las vertientes metafísicas, científicobiológicas y político-sociológicas de la filosofía del estagirita. La apelación a la definición no es, en efecto, un recurso más o menos extemporáneo de la filosofía aristotélica en la medida en que esta filosofía, una vez desembarazada de la caracterización platónica del ser de las ideas (de las ideas como ser por excelencia y presencia de lo originario mismo), buscaba ser explicitación de la capacidad de aquel logos humano (razón, lenguaje) que da efectividad al desvelamiento-verdad de lo que hay, poniendo de manifiesto el logos (la razón) de lo que subyace en la determinación de lo presente y mostrando los principios/causas que dan cuenta de lo presente-determinado (de lo que existe siendo). El tratamiento aristotélico de la definición conforma, así, el marco de la filosofía misma aristotélica como lógica y sabiduría definidoras que hacen aflorar las estructuras, no menos definidas, de la realidad de lo metafísico, de los cauces de lo físico y de lo científico, así como de las exigencias del quehacer ético y político humano, del mismo modo que la cultura occidental, una vez que se vio informada por los planteamientos definidores aristotélicos, se vio abocada a propiciar unos modelos definidores de la realidad global, generando una caracterización de los modos de ser y unos patrones de conducta que siguen teniendo en nuestros días una insospechada vigencia?.

7 Aparte del uso que Aristóteles hace de logos para "definición", el estagirita fue el primero en urilizar el término horismos (acción de limitar, poner límites), que aplica, igualmente, a "definición». Otras veces, utiliza horos (límite, limitar) como "definición", sirviéndose, en este caso, de un término que aparece ya en Homero. Nuestra "definición" (de-finire: poner fines, límites/fronteras) coincide, pues, con el uso aristotélico de horismos y de horos, términos de la familia de semantemas relacionados con "limitar" y «acción de poner límites/fronteras (boritsein, borion, horios, horisma...). Lo sin-límites es, por ello, lo a-oriston (lo sin horos), que Aristóteles usa en plural ( $t a$ aorista) para significar lo meramente potencial y abstracto, lo in-definido, algo que para Aristóteles resulta ser carente de valor metafísico, contrastando con la determinación positiva por excelencia que lo apeiron (lo carente de peras, límite) tenía en la filosofía presocrática.

8 El papel relevante que la definición cumple en la creación de la lógica aristotélica es paralelo a la importancia que otorga Frege, el creador de la lógica actual, a la definición, especialmente en el segundo volumen de los Grundgesetze der Arithmetik. vid, KENNY, A., Introducción a Frege (Madrid, Cátedra, 1997) pp. 185ss.

9 En nuestro «Filosofía y racionalidad diferenciadora", en GINER, S., y GUISAN, E., eds., José Ferrater Mora: El hombre y su obra (Santiago de Compostela, Universidad de Santiago, 1994), 
Puestas así las cosas, hay que hacer notar, sin embargo, que, desde una perspectiva historiográfica, resulta a veces laborioso establecer de modo fiable aquella relación entre filosofía y definición en Aristóteles, habida cuenta de que gran parte de los textos aristotélicos acerca de la definición se prestan a plurales, e incluso contradictorias, lecturas. Conviene, por ello, avisar desde un primer momento que son varios los usos que Aristóteles propone para «definición» 10 (contando que son varios los tipos o especies de definición que pueden distinguirse $^{11}$, como pone de manifiesto, sobre todo, An. Post. II, 8-10) ${ }^{12}$ y que, de

pp. 129-157, hemos tratado de ofrecer una primera justificación de lo que se acaba de decir, intentando mostrar cómo la lógica definidora aristotélica lleva inevitablemente a su creador a una configuración diferenciada de los distintos órdenes de la realidad y del saber, a partir de la cual la cultura occidental generaría una axiología fuertemente diferenciadora, en contra de la tan generalizada opinión de que la lógica aristotélica estaba basada en aquel «distinguer pour unir» que los maritainianos de toda índole contribuyeron en su día a popularizar.

10 No pocos lógicos optan por seguir el ejemplo de R. RoBINSON (cfr. Definition, Oxford, Clarendon Press, 1950, pp. 2-3) y hablar de "definición de 'definición' cuando se trata de abordar los diferentes usos de "definición" que ellos proponen. En relación con ello, resulta ser algo más que una curiosa coincidencia reparar en que ya Aristóteles, al tratar de los diferentes usos/tipos de lo concerniente a la definición, usaba también la expresión "definición de 'definición'" (horos horou): cfr. An. Post. 9, $93 \mathrm{~b} 38$.

11 Se suele seguir diciendo que Aristóteles divide la definición en «real» y «nominal» (cfr., por ejemplo, Robinson, R., Definition, op. cit., pp. 7ss.; PARRY, W. T., y Hacker, E. A., Aristotelian Logic (Albany, State University of New York, 1991), pp. 80ss.; 506). De hecho, sin embargo, Aristóteles no usa tales denominaciones y ya Ross hace años que advirtió acerca de la conveniencia de tener en cuenta que Aristóteles usa "definición» de modo más complejo y plural que la mera referencia a la división real/nominal. A pesar de todo, hay que reconocer que "real" y "nominal" pueden seguir siendo vistos como los dos grandes marcos de referencia en que pueden encuadrarse los diferentes usos y especies de definición con que opera Aristóteles: vid. DEmoss, D., y DeVreux, D., “Essence, Existence, and Nominal Definition in Aristotle's Posterior Analytics II, 8-10", en Phronesis, 33, 1988, pp. 133-154. También, por lo demás, la apelación a la definición real y nominal en Aristóteles puede igualmente servir de base para un diálogo con lógicos y filósofos de nuestros días que se ha ocupado de cuestiones relacionadas con la definición, como puede verse en CARGILE, J., "Real and Nominal Definitions», en Definitions and Definability: Philosophical Perspectives, op. cit., pp. 21-50.

12 Se trata de un pasaje de difícil interpretación en lo concerniente al punto que aquí nos ocupa y que, por ello, sigue atrayendo la atención de estudiosos de la obra aristotélica, como pueden ser GOMEZ-LOBO, A., "Definitions in Aristotle's Posterior Analytics", en O'MEARA, D. J., ed., Studies in Philosophy and History of Philosophy, IX (Washington, D. C., Catholic University of America Press, 1981), pp. 25-46; Demoss, D., y DeVEREux, D., Essence, Existence, and Nominal Definition in Aristotle's Posterior Analytics, II, 8-10, a. c., en nota anterior; ACKRIL, J. L., "Aristotle's Theory of Definition: Some Questions on Posterior Analytics II, 8-10w, en BERT, E., ed., Aristotle on Science: The "Posterior Analytics" (Padua, Editrice Antenore, 1981), pp. 359-384, obra en la que puede igualmente verse (pp. 61-96) el interesante trabajo de J. BRUNSCHWIG, L'object et la structure des Seconds Analytiques, asi como el de Richard SoraBj, Definitions: What Ne- 
entre los usos y tipos de definición que pueden ser rastreados en la doctrina aristotélica ${ }^{13}$, nosotros nos atendremos únicamente a lo que Aristóteles trata como definición en su sentido más estricto y riguroso, es decir, al enunciado o fórmula (logos) ${ }^{14}$ que significa lo to ti en einai (Top. I, 5, 101b37; Met. V, 6, 1016a33-34) o lo ti estit5 de algo indemostrable ${ }^{16}$, ya que "en la definición no

cessary and in What Way? (pp. 205-244). El tema objeto de esta nota ha sido también tratado por M. T. FerejoHn, en sus The Origins of Aristotelian Science (New York, Yale University Press, 1991) y "Definition and the Two Stages of Aristotelian Demonstration", en Review of Metaphysics, 36, 1982, pp. 375-395.

13 Sean cuales fueren tales usos y tipos, ya que sigue abierta la discusión acerca del número concreto de usos/tipos de definición puestos en juego en la obra aristotélica: cfr. BYRNE, P. H., Analysis and Science in Aristotle (Albany, State University of New York Press, 1997), pp. 147149, donde también pueden encontrarse significativas referencias bibliográficas acerca de esta cuestión.

14 De acuerdo con Top. 1, 5, 102a5: "Toda definición es un cierto enunciado/fórmula" (pas horismos logos tis estin), del tipo de "animal bípedo». El logos definicional aristotélico no es, pues, oración, ni nombre, ni enunciado-que-funciona-nominalmente (logos onomatodes: caso, por ejemplo, de "eclipse de luna").

15 Manteniendo la identificación entre lo ti estiy lo to ti en einai que aparece en los textos aristotélicos relacionados, más o menos directamente, con la definición. No abordaremos aquí, por ello, las distinciones que, más allá de lo estrictamente referido a la definición, pueden establecerse entre aquellos dos conceptos, una cuestión que ha sido objeto de múltiples estudios, tanto en lo que concierne a la obra de Aristóteles como en lo relacionado con la interpretación que de esta obra hace Santo Tomás en este punto: vid, acerca de ello, STEIN, E., Ser finito y ser eterno (México, FEC, 1994), pp. 137ss. o el estudio de Bernard LonerGan, en Burrell, D. B., ed., Verbum: Word and Idea in Aquinas (Notre Dame, University of Notre Dame Press, 1967), pp. 16-25.

16 Mientras Top VII, 3 sostiene que el procedimiento silogístico puede llevar a la definición y a lo to ti en einai de la especie, An. Post. II, 3 hace de las definiciones los principios del silogismo, por lo que estrictamente (a) no puede haber definición de lo que aparece demostrado en el silogismo y (b) resulta imposible una demostración silogística de la definición (o silogismo de la esencia): "no hay demostración silogística de aquello de lo que hay definición, pues la definición lo es de lo ti esti y de la ousia, mientras que las demostraciones silogísticas parecen, en cambio, presuponer y dar todas por sentado lo ti estiv: An. Post. II, 3, 90b29-32. A pesar de todo, en los capítulos 4, 8 y 9 de $A n$. Post. II, la afirmación anterior parece exigir matizaciones ulteriores, las cuales, sin embargo, no bastan, a nuestro juicio, a eliminar la contradicción existente entre $A n$. Post. II y Top. acerca de la relación entre la demostración y la definición. En relación con ello, siguen gozando de amplia aceptación las consolidadas opiniones de Maier, Sohsen o Mansion, los cuales sostienen que, mientras que al principio de su obra Aristóteles se inclinó por la demostrabilidad de la definición, la evolución de su doctrina lógica acabaría llevándole a defender la imposibilidad de una tal demostrabilidad: vid. MAIER, H., Die Syllogistik des Aristoteles (Tübingen, Laupp, 1896-1900), II, 2; SOLMSEN, F., Die Entwicklung der aristotelischen Logik und Rethorik (Berlín, Weidmann, 1929), pp. 180ss.; MaNSION, A., "L'origine du syllogisme et la théorie de la science chez Aristote», en Aristote et les problemes de la mèthode (Louvain, Pub. 
se predica nada de otra cosa distinta" (An. Post. II, 3, 93b35). La definición aristotélica, en una acepción estricta, se corresponde con lo que tradicionalmente ha sido caracterizado como la "definición real" (aristotélica), la cual, por su componente universal engendrado en la dinámica de las relaciones entre género y diferencia, es sólo aplicable al desvelamiento de la naturaleza esencial de las especies (eide), pero no de las individualidades singulares, que resultan ser, por ello, indefinibles ${ }^{17}$. La especie (species=aspecto) de $x$ remite, en efecto, la consistencia de lo particular al sentido/significado en que se desvela lo ti esti y lo to ti en einai, la naturaleza esencial de lo presente.

Aun cuando este planteamiento aristotélico de la definición tenga indudables resonancias platónicas, hay que destacar, sin embargo, que aquel planteamiento es, en realidad, deudor del convencimiento adquirido con el tiempo por Aristóteles de que la filosofía del Platón maduro se mostró incapaz de explicar (es decir, "desplegar»la presencia de) lo que sea la especie y lo que puede ser dicho de ella con sentido en la medida en que la especie es revelación de la naturaleza esencial (de la consistencia de la presencia) de lo que es, de la cosa. Hablar con sentido de la especie significará, por ello, para Aristóteles abandonar la pretensión de Platón de hacer del eidos la unidad suprema subsistente en sí misma, aquello que está en el ámbito de la idea, de lo que "es auténticamente», por oposición a la debilidad ontológica de lo que aparece-presente. Oponiéndose a Platón, Aristóteles ve en la especie aquello que proporciona significado esencial a las cosas, pero no en virtud de una supuesta presencia, primaria y radical, de la especie frente a lo que aparece, sino sólo porque la referencia a la especie per-

Univ., París, Béatrice-Nauwelaerts, 1961), pp. 57ss. Para una opinión diferente (que no ha encontrado, por lo demás, demasiados seguidores), vid. Cherniss, A., Aristotle's Criticism of Plato and the Academy, I, 2 (New York, Russell \& Russell, 1962), p. 34. Por nuestra parte, nos inclinamos a creer que estos planteamientos tradicionales deben ser revisados, tratando de eliminar las aparentes divergencias de An. Post. II, 3-10. Para ello, hay que tener en cuenta los diferentes significados de "definición" que alli son puestos en juego, de tal manera que, mientras que la definición en sentido estricto, es siempre para Aristóteles «el enunciado indemostrable de lo ti esti de lo indemostrable», otras acepciones aristotélicas menos estrictas de la definición podrían relacionarse con un tipo de silogismo capaz de "poner en claro", aunque no de "proban", lo ti esti de un hecho demostrable. Todo ello ha sido examinado por BYRNE, P. H., Analysis and Science in Aristotle, op. cit., pp. 147-163. Vid, también, LANDOR, B., «Aristotle on Demonstrating Essencen, en Apeiron, 19, 1985, pp. 116-132.

17 Cfr. An. Post. II, 13, 97b25-28: «Toda definición es siempre de lo universal (aei d'esti pas horos katholou) pues no dice lo que es sano para un ojo, sino para todo ojo o para una especie determinadam. 
mite a lo uno mostrar su consistencia separada (de-limitada, de-terminada, definida) de lo otro. Definir la especie de $x$ será, entonces, la tarea de un logos que de-limita (separa) las especies definidas de la Unidad in-conmensurable (in-definible) del ser originario (de lo xynon, physis, arche). Con Aristóteles, la presencia y el ser pasan a constituirse como definición y separación.

\section{El espacio lógico del género y de la diferencia}

La especie se define por el género y la diferencia, los cuales revelan y despliegan la esencia/substancia ${ }^{18}$ de una especie dada y concretan el marco de los predicados (esenciales) que el sabio ha de tratar de "cazar" (thereuein: An. Post. II, 13, 96a23) poniendo en práctica un método adecuado para ello ${ }^{19}$. Género y diferencia no son, sin embargo, presenciación de una realidad originariamente consistente (la idea platónica), sino los elementos que informan la especie (eidos) a la que definen, separándola de las otras especies, algo sobre lo que insistirá Top. VI ${ }^{20}$. La función separadora-delimitadora es inseparable del ejercicio del logos definidor toda vez que la apelación de éste al género y a la diferencia sólo tiene sentido en la medida en que "es preciso que el género separe de los otros géneros, y la diferencia de lo que está en el mismo género" (Top. VI, 3, 140a27-29)21. Un

18 Cfr. An. Post. I, 22, 83a39-b1: "(el sujeto) se predicará como ousia, es decir, como género y diferencia".

19 La tan conocida metáfora de la filosofía como «caza" del saber (metáfora de la que tanto partido supo sacar, entre nosotros, Ortega y Gasset) enlaza, así, con la concepción aristotélica de la definición como caza metódica de los atributos esenciales del eidos. El origen de esta metáfora se encuentra, sin embargo, en Platón, algo sobre lo que recientemente ha insistido LuRI Medrano, G., El proceso de Sócrates. Sócrates y la transposición del socratismo (Madrid, Trotta, 1998), pp. 70-72.

20 Cfr., por ejemplo, VI, 3, 140a27-29; VI, 4, 141b22-34; VI, 5, 144a23-27. En la lógica actual se nos dice que, siendo la especie una conjunción de dos elementos o propiedades lógicamente independientes (género y diferencia), la clase de $x$ (especie) está incluida en la clase de $y$ (género) pero separada por la diferencia de las otras clases que pueden estar dentro de $y$. cfr. Searle, J. R., "Determinables and the Notion of Resemblance», en Proceedings of the Aristotelian Society, 33, supp. vol., 1959, pp. 141-143.

21 Para Aristóteles, al fin y a la postre, "en materia de definiciones, la discusión se plantea la mayoría de las veces sobre si algo es idéntico o distinto (tauton be beteron)»: Top. I, 5, 102a8. La repercusión de este tipo de planteamientos en la obra científico-biológica de Aristóteles ha sido destacada por A. GotThelf (First Principles in Aristotle's Parts of Animals) y D. M. BALME (Aristotle's Use of Division and Differentiae), trabajos ambos aparecidos en GoTTHELF, A., y LENNox, J. G., eds., Philosophical Issues in Aristotle's Biology (Cambridge, Cambridge University Press, 1987), pp. 167-198 y 69-89, respectivamente. 
pretendido logos definidor que no tuviera función separadora-delimitadora alguna sería, por el contrario, logos en que se manifiesta en toda su generalidad la presencia misma de lo presente, "lo que se da en todas las cosas" y no podría ser tenido como horismos (de-finición) justamente porque «lo que se da en todas las cosas no separa de ninguna en absoluto" (Top. VI, 3, 140a29-30) 22. La función de-limitadora, pues, que la definición ejerce en la diferenciación de las especies entre sí es una función que se explicita justamente en y por el juego de relaciones que pueden establecerse entre el elemento que da primacía a lo común que religa especies (el género) y el elemento que explícitamente ejerce la de-limitación entre especies (la diferencia) a partir de lo ofrecido en lo genérico 23 . La especie "toro" y la especie "hombre" (por utilizar los ejemplos de Topicos y de Categorias) quedarán, así, delimitadas y separadas en su definición, atendiendo a la diferencia (diaphora) aportada en la definición de ambas especies a partir de la convergencia que el género (genos) "animal» introduce entre ambas especies.

Lo dicho no impide, a pesar de todo, que Aristóteles se muestre convencido de que, desde una perspectiva lógica y aun siendo necesarios ambos elementos para la definición, el elemento convergente (género) cobra un mayor protagonismo que el elemento "diferencia" en el espacio del logos definidor ${ }^{24}$. El

22 Análogamente, si el logos tampoco separa lo que está en el mismo género, será un logos sin diaphora (diferencia), un logos in-diferenciado y no un auténtico logos de-finidor: Top. VI, 3 , 140a31-33.

23 Prescindimos aquí de las, a veces, no poco fluctuantes opiniones aristotélicas acerca del género y de la diferencia en su aplicación a referentes no substanciales, tema acerca del cual nos remitimos a GRANGER, H., "Aristotle and the Genus-Species Relation", en Southern Journal of Philosophy, 18, 1980, pp. 37-50; «Aristotle on Genus and Differentia», en Journal of the History of Philosophy, 22, 1984, p. 4.

24 H. Granger, en su Aristotle on Genus and Differentia (citado en nota enterior), ha sostenido que la doctrina aristotélica de definición ofrece una evolución, con tres pasos: (a) género y diferencia son substancialmente diferentes y el género es el elemento más importante en la definición; (b) género y diferencia son substancialmente semejantes y tienen una importancia pareja; (c) género y diferencia son substancialmente semejantes, pero la diferencia es ya el elemento más importante de la definición. Es innegable que esta visión evolutiva de la doctrina aristotélica de la definición resulta no poco atractiva para el historiador de la filosofía y que está, además, en consonancia con la atención que se está hoy volviendo a prestar a la evolución del pensamiento de Aristóteles (vid, por ejemplo, WLANS, W., ed., Aristotle's Philosophical Development. Problems and Prospects, Lanham, Rowman \& Littlefield Pub., 1996) en la línea que preconizaran, en la década de los años veinte, JAEGER (Aristoteles. Grundlegung einer Geschichte seiner Entwicklung: Berlin, Weidmannsche Buchhandlung, 1923; hay trad. cast.) y F. SOLMSEN, en su Die Entwicklung der aristotelischen Logik und Rethorik (Berlin, Weidmannsche Buchhandlung, 
género, en efecto, siendo «lo que se da potencialmente (kata dynamin) en muchas cosas» (An. Post. II, 13, 96b9-10) y «lo común a todos» (An. Post. II, 14, 98a2) ${ }^{25}$ que se dice "sobre más cosas que la especie y la diferencia" (Top. IV, 1, 121b13-15), es lo que "predica el ti esti de muchas cosas que se diferencian en su eidos (específicamente)" (Top. I, 5, 102a31-32), de tal manera que el género, revelador de lo ti esti, es un predicado substancial. A la diferencia, sin embargo, no puede aplicársele la determinación lógica de lo substancial 26; es, meramente, cualidad (poion ti) ${ }^{27}$. El género es, por ello, lógicamente más inteligible y su

1929). A pesar de ello, no creemos que sea el mejor camino para dar cuenta de las relaciones que la doctrina aristotélica de la definición establece entre el género y la diferencia. De un lado, en efecto, en los textos aristotélicos relacionados con la definición, el historiador de la filosofía dificilmente puede llegar a establecer con seguridad aquella evolución de la que se nos habla, habida cuenta de que aquellos textos ofrecen los puntos destacados por Granger de un modo que no se corresponde con la cronología establecida hoy día para las obras del estagirita. De otro lado, y ello es más importante para nosotros, la evolución defendida por Granger no toma suficientemente en consideración que, desde un principio, Aristóteles destacó la función di-ferenciadora y de-limitadora del logos definidor. Alejándonos, por ello, de un planteamiento evolutivo de la teorla aristotélica de la definición, sostendremos, por nuestra parte, que la importancia, mayor o menor, otorgada por Aristóteles al género o a la diferencia en el discurso definidor está en función del punto de vista lógico u ontológico adoptado por Aristóteles. A pesar de ello, nuestro trabajo es en parte deudor de algunas importantes aportaciones que hace Granger en su estudio, que, desafortunadamente, no ha tenido la difusión que a nuestro juicio merece.

25 Este capítulo 14 de $A n$. Post. Il está dedicado precisamente a poner de manifiesto los diferentes modos que permiten establecer el género como comunidad de propiedades.

26 Mientras que, por el contrario y desde esta perspectiva lógica, el género es «lo que subyace a las diferencias (to hypokeimenon tais diaphorais)": Met.. V, 28, 1024b4. De ahi que "el género es el sujeto (bypokeimenon) del cual la demostración (apodeixis) indica las afecciones y accidentes en sín, según An. Post. I, 7,75b1-2. De todas formas, nos remitimos a lo que más adelante diremos acerca de la configuración categorial que la diferencia adquiere en otras obras aristotélicas relacionadas con la cuestión de la definición, advirtiendo, desde ahora y siguiendo a Donald MORRISON, que «no resulta fácil llegar a comprender claramente la concepción aristotélica de la diferencia. Las teorías de Aristóteles sobre la división, sobre la definición, sobre la esencia y la substancia, sobre la explicación científica y la demostración, influyen todas ellas en la noción de diferencia y, a su vez, se ven todas ellas afectadas por esta nociónn: cfr. "Le statut catégoriel des différences dans l''Organon'», en Revue philosophique de la France et de l'etranger, 2, 1993, p. 147. Por lo demás, nuestro trabajo defenderá una opinión acerca de la naturaleza de la diferencia en la obra de Aristóteles que no coincide con lo defendido por D. Morrison en su (harto recomendable, a pesar de lo dicho) estudio citado en torno a la caracterización pluralista de la categoría metafísica de la diferencia, interpretación que el propio Morrison se cuida de presentar como siendo en absoluto concluyente.

27 Cfr. Met. V, 28, 1024b4-6: «En las definiciones (logois), es género el primer elemento (to proton enyparchon) que se dice/enuncia en la esencia (en to ti esti), del cual se dicen que son diferencias las cualidades (poiotetes)m. Para la lógica aristotélica, en efecto, resulta evidente que «la diferencia no es el género de nada» y ello porque uninguna diferencia significa lo ti estin de algo, 
conocimiento es anterior al de la diferencia, toda vez que las substancias son más accesibles al conocimiento y gozan de preeminencia epistémica sobre las determinaciones no substanciales.

La importancia de lo común-genérico en la configuración lógica de la definición aristotélica se pone también de manifiesto en que es a veces detectable en los primeros escritos lógicos de Aristóteles un concepto de definición en el que ésta no es vista como estricta separación delimitadora en sí misma, sino como conjunto de notas, cada una de las cuales tiene mayor extensión que lo que es objeto de la definición, el cual se muestra justamente en la interrelación de aquellas notas, interrelación que, a su vez, conforma el predicado coextensivo y esencial de lo definido. El logos definidor apunta, en este caso, más a lo común que lo rigurosamente diferenciador/separador. De hecho, en la lógica del primer Aristóteles, la diferencia tiene, ella también, una extensión mayor que lo definido, al igual que ocurre con el género, por lo que Top. I, 4, 101b18-19 justifica que la diferencia no sea expresamente incluida en la relación de los predicables precisamente porque "teniendo una naturaleza genérica (genike), ha de ser colocada en la rúbrica del género" 28 . Ello no puede significar que género y diferencia sean lo mismo ni que la diferencia vaya a participar del género, toda vez que «lo que participa del género es o especie (eidos) o individuo (indiviso, atomon), mientras que la diferencia no es ni especie ni individuo; es, pues, evidente que la diferencia no participa del género" (Top. IV, 2, 122b20-23) ${ }^{29}$ y

sino más bien su cualificación (poion $t z$ ), que es lo que hacen, por ejemplo, 'terrestre' y 'bípedo'n: Top. IV, 2, 122b15-18. Vid., igualmente, Top. VI, 6, 144a15-19; Cat. 5, 2b29ss. A ello se ha referido GRANGER (Aristotle on Genus and Differentia, a. c., p. 5): "El género, en cuanto lo ti esti de un deffiniendum substancial es una substancia o categoría substancial; la diferencia, en cuanto poion ti, es una no-substancia o categoría de la cualidad".

28 En su comentario introductorio a la traducción, también a él debida, de Tópicos, BRUNSCHWIG ha hecho notar acertadamente que la relación aristotélica de los predicables (definición, género, propiedad, accidente) estaba destinada a mostrar que toda predicación atributiva ha de quedar incluida en una división cuatripartita, adecuadamente explicitada: "Si el predicado es coextensivo y esencial, es definición; si es coextensivo y no-esencial, es propiedad; si es no-coextensivo y esencial, es género; si es, en fin, no-coextensivo y no-esencial, es accidente" (Aristote. Topiques (I-IV), París, Les Belles Lettres, 1967, p. XIVIII). Arendiendo, pues, a su predicabilidad, la diferencia coopera a expresar lo to ti en einai de las cosas, pero desde un ángulo asimilable a las características predicativas del género, de lo que significa lo ti esti de las cosas.

29 Hay que tener en cuenta que, en lenguaje aristotélico, "participar de algo" significa "admitir la definición (logos) de lo participado». De ahí que "las especies participan de los géneros, mientras que los géneros no participan de las especies, pues la especie admite la definición del género y el género no admite la de la especie» (Top. IV, 1, 121a10-15). En otros pasajes de Tópicos, ARISTOTEles llegará incluso a decir que la especie y el género, siendo "sinónimos", tienen 
que "la diferencia no es género de nada" (Top. IV, 2, 122b15). Con ello, Aristóteles puede retomar lo que antes habíamos venido exponiendo acerca de la primacía lógica que el género tiene sobre la diferencia en el discurso (logos) definidor: "Puesto que a algunos les parece que también la diferencia se predica ( $\mathrm{ka}$ tegoreisthai) en lo ti estin de las especies, hay que separar (choristeon) el género de la diferencia (...): primero, el género se dice sobre mayor número de cosas que la diferencia; después, que a la aplicación de lo ti estin le es más pertinente que se diga el género que no la diferencia (pues el que ha llamado animal al hombre indica más lo ti estin del hombre que el que le ha llamado pedestre); en fin, la diferencia muestra siempre la cualificación (poioteta) de un género, mientras que el género no la muestra de la diferencian (Top. IV, 6, 128a20-30) ${ }^{30}$.

Todo ello está en consonancia con las líneas maestras de la doctrina lógica de la definición establecida en Tópicos, a saber, que la determinación de los predicables no accidentales (género, propio) está en función de las condiciones que ha de cumplir la definición correcta, teniendo siempre presente que, de entre aquellas condiciones/predicables, es justamente el género el que "en mayor grado muestra lo ti estin de lo definido" (Top. VI, 1, 139a31-32) 31 , de tal manera que la definición ha de mostrar que el primero de los elementos de la fórmula definicional corresponde justamente al género bajo el que cae el sujeto de la fór-

la misma definición. Nada de ello puede decirse, sin embargo, de la relación que pueda establecerse entre la especie y la diferencia.

30 También Met. V, 28, 1024b4-6 se refiere al género como "el elemento primero que en las fórmulas definicionales (en tois logois) se dice en relación con lo ti esti y del que las diferencias son referidas como cualidades (poiotetes)". Cfr., también, Met. VII, 7, 1032b31-1033a9.

31 Al estar Tópicos situado en el plano lógico-dialéctico (atendiendo al sentido que Aristóteles da al razonamiento "dialécticon), es comprensible que el género sea relacionado con lo ti esti de un modo más directo que lo que pueda estarlo la diferencia. En la tesitura de Tópicos, en efecto, nos es más accesible lógica y lingüísticamente el género que la diferencia, ya que paramos mientes y conocemos en primer lugar lo común y no lo diferenciador. Así, "el género es lo más conocido de todo" (Top. VI, 11, 149b17) y ues preciso que la diferencia venga después del género" (Top. VI, 6, 144b10). Ello está relacionado con la ambigüedad que, a veces, confiere Analíticos a la noción de lo ti esti, según sea visto como lo primero en relación a nuestro conocimiento o, por el contrario, como lo que es en sí lo primero y lo más inteligible. En el primer caso, se trata de un significado amplio de lo ti esti, que hace posible su inclusión tanto en la demostración como en la definición. En un sentido más estricto (y al que, por lo demás, suele acogerse Aristóteles), lo ti esti, visto como lo primero y lo más inteligible en sí mismo, sólo puede darse en la in-mediatez de la definición, no en el proceso mediado (es decir, en función de un término medio) de la demostración. Vid, acerca de ello, Byrne, P. H., Analysis and Science in Aristotle, op. cit.., pp. 128ss. 
mula. Siendo, entonces, el género la mostración de lo ti esti de la cosa, a la diferencia le corresponde separar/delimitar lo que cae bajo un mismo género, es decir, traer a colación lo que no es semejante (homoion) dentro de la ousia de algo y ello se realiza en función de la cualidad (poiotetos), ya que «la característica de la cualidad es que se diga con relación a ella lo semejante y lo desemejante (homoion kai anomoion): Cat. 8, 11a18-19. En la configuración lógica de su doctrina de la definición, a Aristóteles le basta, entonces, destacar la función cualificadora de la diferencia, el que la diferencia sea un poion $t i$, sin relación especial con la mostración de la esencia de lo definido, reservada al género ${ }^{32}$.

A la vista de ello, acaso no ande demasiado descaminado decir que, en su visión lógica del tema de la definición, Aristóteles es, de algún modo ${ }^{33}$, solidario con aquella explicitación de armonía convergente que caracterizó el nacimiento de la filosofía, de tal modo que da la impresión de que el Estagirita qui-

32 Cuando llegue el momento de abordar el alcance ontológico de la definición, las cosas variarán radicalmente ya que, en este plano ontológico, la diferencia quedará equiparada a la forma (morphe), especie (eidos) y, en definitiva, a la esencia, mientras que el género será la materia indeterminada que sólo tiene en potencia (dynamei) su propia physin. De ahí que la diferencia/forma ues más physis que la materia/género, porque decimos que una cosa es lo que es cuando existe actualmente (entelechia) más que cuando existe en potencia (dynamei)n: Phys. II, 1, 193b6-8.

33 "De algún modo", puesto que no se debe olvidar que la doctrina aristotélica encierra, en todo caso y en definitiva, la apelación a un logos que es separación-delimitación. El logos definidor aristotélico no es nunca, en sentido estricto, explicitación de la comunidad originaria de lo presente (las cosas) porque "lo que se da en todas las cosas no separa de ninguna en absoluto" y no puede entrar, por ello, en el ámbito de-finidor (de-limitador, de-terminante). Con ello no parece avenirse demasiado bien Top I, 5 y I, 7, que relacionan la cuestión de la definición con la de la identidad, por más que esta relación no encuentre una continuidad apreciable a lo largo de los propios Tópicos. En este caso, resulta razonable suponer, con Brunschwig, que la referencia a la identidad fue elaborada por Aristóteles de modo independiente y con anterioridad a la redacción de la mayor parte de Tópicos, lo que propiciaría la imagen de un Aristóteles preocupado por no apartarse de la línea armónico/identificadora del pensamiento presocrático y platónico, antes de centrarse en el tratamiento del logos definidor/separador. A propósito de lo dicho, conviene tener en cuenta que el paralelismo introducido por Topicos entre identidad y definición no puede parangonarse sin más con las relaciones entre identidad y definición abordadas en los modelos formales de la lógica de nuestros días, como puede ser el caso de Jaako HiNTIKKA, en su Towards a General Theory of Identifiability, en FETZER, H.; SHATZ, D., y SCHLESINGER, G. N., eds., Definitions and Definability. Philosophical Perspectives, op. cit., pp. 161-183. En relación con ello, una estrategia recomendable puede ser la de contrastar las aportaciones de Hintikka con las versiones que acerca de la relación identidad/definición llevaron a cabo, entre otros, Frege, Whitehead-Russell, Hempel, Carnap, Cohen-Nagel o Quine, autores algunos de los cuales han sido estudiados, en el punto concreto al que aquí nos estamos refiriendo, por OrTiz Hill, C., $R e-$ thinking Identity and Metaphysics. On the Foundations of Analytic Philosophy, op. cit. 
zás estaba convencido de que podía hacer compatible aquella orientación con las exigencias del logos definidor reclamado por Sócrates y Platón, como puede quedar apoyado en una lectura de Tópicos. Sin embargo, no faltan en esta misma obra textos que apuntan en otra dirección, alineada con la defensa de una más explícita caracterización del logos definidor/separador. Así, en el difícil pasaje de Top. VII, $3^{34}$, el género y la diferencia parecen vistos de modo homogéneo como los componentes de la definición. En este texto, Aristóteles, dando por supuesto que a la definición se puede llegar por el procedimiento silogístico, da igualmente por descontado que "este silogismo de la definición" viene dado por la suma de los atributos esenciales, colocados en pie de igualdad: «Es posible llegar por silogismo a la definición y a lo to ti en einai. En efecto, si la definición es logos que muestra lo to ti en einai de la cosa y si es preciso que los predicados contenidos en la definición sean los únicos que se predican esencialmente (en to ti estin) de la cosa y si los géneros y las diferencias son los predicados esenciales (en to ti estin) de la cosa, es claro que, si se toman los predicados que son los únicos que se atribuyen a la cosa, el logos que los contenga será necesariamente una definición; porque no puede ser otra la definición, ya que no hay ningún atributo esencial más de la cosa (que los contenidos en aquel logos)»35.

34 Se trata de un texto que parece haber sido redactado con posterioridad al cuerpo básico constitutivo de Tópicos y que fue luego incorporado a esta obra, como sucedió, por lo demás, con otros apartados de los mismos Tópicos. Porque no entra dentro de los límites de nuestro estudio profundizar en esta cuestión, hagamos simplemente notar aquí que Top. VII, 3 (al igual que Top. VII, 5) pone la definición en relación directa con el razonamiento deductivo (syllogismos), en consonancia con lo que Top. I, 8, 103b2-3 había establecido, a saber, que los predicables son el punto de partida, los instrumentos de realización y los términos de referencia de aquel razonamiento. La relación de la definición con el razonamiento demostrativo (apodeixis) es muy otra ya que, en este caso y al menos en lo concerniente al sentido más estricto de lo ti esti, no puede darse demostración de lo ti esti revelado en la definición ni, por consiguiente, puede llegarse a una tesitura lógica que pretenda deducir la esencia-definida: An. Post. II, 8, 93b16-17. Las dos posturas señaladas se corresponden con las diferencias que afectan al punto de partida de Tópicos (el syllogismos, como opuesto a la epagoge (inducción): Top. I, 8, 103b2-9; I, 12, 105a10-19) y al de Analiticos (la apodeixis o demostración científica). Se trata de la diferencia entre el espacio de lo dialéctico y el de lo demostrativo, analizada en Top. I, 1, 100a25ss.; I, 10, 104a3ss.; An. Pr. I, 1, 24a22ss. Vid., acerca de ello, BrodY, B. A., "Towards an Aristotelian Theory of Scientific Explanation", en Philosophy of Science, 39, 1972, pp. 20-31.

35 Cfr. Top. VII, 3, 153a15-22. En consonancia con ello, Top. VII, 5, 154a25-30 afirmará igualmente que es imposible que la definición llegue a ser silogismo si no se ha conseguido la (difícil) tarea de ver que una conclusión dada encierra el género y la diferencia y que ambos se predican en el ti esti de la cosa. Sin embargo, Top. VII, 5, 154b24-33 dirá explícitamente que, para negar que estamos ante una definición correctamente establecida, basta con mostrar que no 
Esta concepción del logos definidor como suma de atributos esenciales puestos en pie de igualdad no es, sin embargo, la concepción dominante en Tópicos, obra en la que la definición es tratada, por lo general, como unidad en sí misma, dotada de unas propiedades jerarquizadas en función de los predicables estudiados en la obra en cuestión, cosa que no ocurre con la caracterización que de la definición ofrece Top. VII,3, perteneciente, probablemente, a una redacción posterior, no relacionada ya con las cuestiones que dieron origen a la doctrina aristotélica acerca de los predicables ${ }^{36}$. A mayor abundamiento, hay que hacer notar igualmente que el libro I de Tópicos (también redactado con posterioridad a los libros centrales de esta obra) hace una explícita llamada a poner a la diferencia en pie de igualdad con el género con vistas a poner de manifiesto «lo ti estin de las cosas", toda vez que "por lo general, utilizamos las diferencias características de una cosa para aislar el logos propio de la ousía de esa cosa» (Top. I, 18, 108b4-6). En todo ello está latiendo el convencimiento aristotélico de la función creativa de la definición (tan acertadamente denunciada por Frege), consecuencia inevitable de la mezcla entre lo lógico y lo ontológico tan característica del pensamiento griego y que acabará encontrando un singular acomodo en la teoría aristotélica de la definición, como trataremos de desarrollar a continuación.

\section{Lógica y ontología en el discurso definidor aristotélico}

La configuración lógica de la definición aristotélica es deudora del supuesto de que ni el Ser ni lo Uno son géneros y de que, por ello, sólo podemos contar con los géneros en que se muestra la realidad estructurada lógicamente, por lo que, en este caso, "género" y "eidos" son conceptos convertibles, quedando muy en segundo plano el papel jugado por la diferencia en la definición ${ }^{37}$. Al llegar

aparece el género. Esta falta de correspondencia parece poner de manifiesto lo que otras veces ha sido señalado, a saber, que, aun dentro de un mismo capítulo de Tópicos, podemos toparnos con pasajes redactados en tiempos diferentes.

36 BRUNSCHWIG ha hecho notar que la concepción "horizontal" de la definición, tal como aparece en el libro VII de Topicos, es harto diferente de la concepción "vertical" de la definición que ofrece el libro VI de aquella misma obra y que se da, igualmente y por lo general, a lo largo de todo el tratado de Tópicos. Esta concepción «vertical» es la que da pie a la teoría de los predicables, lo que no ocurre con la doctrina "horizontal" de la definición, de redacción posterior, que no guarda una relación especialmente directa con los temas básicos del tratamiento lógico de los predicables.

37 En su aplicación al campo de la definición, la lógica aristotélica se opone, pues, directamente a la doctrina platónica que trataba el Ser y lo Uno como géneros. De ello se hace eco 
aquí, conviene tener presente que la lógica aristotélica surge como búsqueda del adecuado ejercicio de la palabra (logos) en el marco del dia-logos, de la conversación/disputa dialéctica, lo que llevó a Aristóteles a ahondar en la dinámica del "silogismo dialéctico" con vistas a poner de manifiesto la consistencia de lo que se dice por el hablante frente a las objecciones de sus interlocutores ${ }^{38}$. Asi, T6picos se centra, fundamentalmente, en el espacio del logos-palabra, el espacio (a) de los argumentos (logoi) y de sus elementos constitutivos (proposiciones, protaseis); (b) de los razonamientos deductivos (syllogismot) y de los problemas (problemata) sobre los que versan los silogismos; (c) de las expresiones y elementos lingüísticos básicos (los predicables), a partir de los cuales se originan (ginontai) tanto las proposiciones como los problemas.

Al crear la lógica, Aristóteles recogió, pues, la herencia de aquella tradición del pensamiento griego que hacía del logos-palabra el campo mismo en el que se pone en juego el lugar (topos) propio de la presenciación de lo presente, de las cosas que son. En la filosofía aristotélica "las cosas que son" no apunta, por ello, a algo en y por sí mismo existente en una presencia autónoma y ajena al decir, muda. Lo que "es", en efecto, son las cosas que son, lo presente. Ahora bien, lo presente tiene que presenciarse, desvelarse, si es que no se quiere hacer inviable cualquier referencia a la existencia de lo que es y lo presente se presencia justamente en el logos-palabra y es inseparable de su patentización y manifestación lingüísticas: lo que es, es aquello de lo que se dice que es (o, si se quiere, lo no-linguístico pero en cuanto dicho y expresado, manifestado lin-

especial Tópicos, obra que, como ha hecho notar Grene, opera con un débil y poco técnico significado lógico de "género" (un significado que es todavía operativo en Met. V, 7, 1016b33): lo que cae bajo un mismo género no sólo no difiere substancialmente sino, tampoco, numéricamente ya que las diferencias numéricas se dan entre elementos que, perteneciendo a distintas estructuras lógico-genéricas, difieren en su forma. Las diferentes formas dentro del mismo "género" lo que provocan son diferencias "por más o menos" o "por exceso o defecto": vid GreNE, $M$., "Is Genus to Species as Matter to Form? Aristotle and Taxonomy", en Synthese, 28, 1974, pp. 51-69.

38 De este modo, en efecto, justifica Aristóteles el contenido central de Tópicos: «El propósito de este tratado es encontrar un método a partir del cual podamos razonar deductivamente (sylloguitsesthai), apoyándonos en ideas admitidas (ex endoxa), sobre cualquier problema que se nos proponga y, gracias al cual (método), si nosotros mismos sostenemos una afirmación (logos), no digamos nada que le sea contrarion (Top. I, 1, 100a18-21). Habrá que dejar para otra ocasión examinar con detenimiento las analogías que pueden darse entre lo aquí dicho y la caracterización socrática del método elénctico como motor de la dialéctica característica de los diálogos socráticos de la obra de Platón: vid, acerca de ello, nuestro Sócrates y el problema del conocimiento. Ensayos sobre el Menón, op. cit., pp. 63ss. 
güísticamente), siempre bien entendido que, según Aristóteles, el discurso acerca de lo que es, ha de modularse en función de las proposiciones que enuncian los diferentes modos de ser (categorias) ${ }^{39}$ que pueden tener los referentes de los componentes lingüísticos (predicado/sujeto) de aquellas proposiciones.

Top. I (un texto probablemente escrito con posterioridad a los libros centrales de Tópicos) es especialmente deudor de aquella simetría y coimplicación entre el orden de lo que se dice ( $t a$ legomena) y el de lo que es ( $t a$ onta) y, a partir de aquí, de la relación existente entre lo que se dice (se predica, kategoreitai) de algo de un sujeto y lo que se da (pertenece, hyparchei) en un sujeto concreto, visto todo ello fundamentalmente desde la óptica de la palabra (logos) ya que lo que se predica de algo como de un sujeto es aquello (definición, género) que dice su esencia, su $t i$ esti, su to ti en einai y, en consonancia con ello, lo que está en un sujeto es visto, a su vez, como lo dicho (legomenon) acerca de lo que pertenece a un sujeto.

Al igual que Top. I, también Categorías parte de la relación entre lo que se predica de algo como de un sujeto y lo que está en un sujeto dado ${ }^{40}$, pero tratada ahora aquella relación no desde el logos-palabra (como hizo Top. I), sino desde el mirador de lo que es y de los modos de ser. De ahí que tanto el orden de lo que se predica de algo como de un sujeto como el orden de lo que está en un sujeto sean, ambos, cosas que son: de las cosas que son (ton onton), algunas se dicen de algún sujeto, pero no están en ningún sujeto (substancias segundas: las especies y sus géneros); otras, están en un sujeto, pero no se dicen de ningún sujeto (propiedades, características, diferencias); otras se dicen de un sujeto y están en un sujeto; otras no están en un sujeto ni se dicen de un sujeto (substancias primeras, las entidades individuales): Cat. 2, 1a20-1b9.

La orientación introducida por Categorías, en comparación con la orientación dominante en Tópicos, acentúa la función delimitadora del logos en su re-

39 Aunque sea de pasada, hagamos notar aquí que la complejidad que encierra una doctrina de los modos de ser, cuando esta cuestión es abordada con la profundidad exhibida por Roman INGARDEN en su Der Streit um die Existenz der Welt, I (Tübingen, Max Niemayer, 1964) va más allá de lo que, en este punto, da a conocer Aristóteles.

40 Lo que se predica de algo como de un sujeto (bypokeimenon) es lo que se dice de ese sujeto de un modo tal que lo que se dice (legetai) de lo dicho (de lo predicado, kategoroumenon) se dice (rethesetai) también del sujeto: Cat. 3, 1b10-12. De otro lado, estar en un sujeto significa aquello que se da en una cosalsujeto concreto (pragma) sin ser parte separable (meros) suya, no pudiendo existir fuera (choris) de aquello en lo que está: Cat. 2, 1a24-25. 
lación con lo existente ya que, en última instancia, el logos se actualiza en su vinculación con los individuos existentes (las substancias primeras) puesto que las cosas o bien se dicen de las substancias primeras como sujetos, o bien están en ellas como como sujetos, por lo que si las substancias primeras no existiesen, sería imposible que existiera alguna de las restantes cosas: Cat. 5, 2a33-34; 2b5ss. Las substancias primeras son, así, la realidad por excelencia, lo que ante todo merece ser llamado "substancia" (Cat. 5, 2b37-38) porque son estas substancias las que "hacen de sujeto para todas las demás cosas" y es por relación a ellas como hay que estipular la naturaleza y el ordenamiento de lo que se predica o de lo que está en ellas. De este modo, "de entre las substancias segundas, la especie (eidos) es más substancia (mallon ousia) que el género puesto que está más cerca de la substancia primera» (Cat., 5, 2b7-8), mientras que no es posible establecer ordenamiento/clasificación entre las especies pues «ninguna es más substancia que la otra ya que explicando al hombre individual como hombre no se explicará más apropiadamente que explicando el caballo individual como caballo" (Cat. 5, 2b23-26).

Al hilo de todo ello, Categorias pone su punto de mira en la ousia, en lo que no está en un sujeto ${ }^{41}$ y si únicamente la especie y el género son substancias (segundas), lo son en la medida en que sólo las especies (eide) y los géneros «de entre las cosas que se predican» son capaces de hacer aflorar (deloi) la substancia primera, al ser mostración (eidos = species $=$ aspecto, mostración) y presenciación de lo presente-individuo (Cat. 5, 2b29ss.). La substancias segundas (eidos, genos) revelan la presenciación de lo presente-individuo justamente en la medida en que tienen capacidad de decir/predicar lo ti esti, la esencia de la prote ousia, del individuo-presente, capacidad que se hace manifiesta en y por el hecho de que el logos (definición) de lo que sea la especie y el género se aplica (se predica) al sujeto-substancia primera, mientras que las cosas que meramente están en un sujeto (propiedades/características) no son definicionalmente predicables de la substancias primeras y son, por ello, incapaces de hacer aflorar lo ti esti de estas substancias.

41 Tópicos mira primordialmente a lo to ti en einai y a lo ti esti, la esencia que se predica de un sujeto. No es, por ello, ninguna casualidad que, al establecer Top. I, 9, la lista de predicaciones (kategoriai) en las que se dan los "predicables", la ousia de Categorias se vea sustituida por lo ti esti. Ello, claro está, no debe llevar a la conclusión de que la clasificación de las categorías que hace Topicos sea esencialmente diferente de la que aparece en Categorias, atendiendo a lo que hemos dejado dicho acerca de la convertibilidad establecida por Aristóteles entre el orden de lo que se dice y el de lo que es. 
La diferencia, por su parte, no siendo ni especie ni género (las únicas substancias segundas), tendrá que verse asimilada a las propiedades/características no substanciales ${ }^{42}$, las cuales no se predican del sujeto. Dejando, sin embargo, las cosas así, sin más, se entraría en contradicción con lo que Categorías trata de poner de manifiesto, a saber, la función delimitadora que encierra la definición como revelación de lo que es. Al predicarse, en efecto, el género de la especie, ésta queda delimitada/separada de las cosas en general, pero, con ello, se pone tan sólo en juego una delimitación harto pobre del amplio espectro de lo que es, de lo presente ${ }^{43}$, con lo que difícilmente podría convertirse la definición en el eje de lo que propiamente debe decirse acerca de lo real.

Buscando ahondar en la proyección delimitadora de la definición, Top. VII dejó entrever la necesidad de poner también en juego a la diferencia como elemento integrante de la definición en pie de igualdad con el género. No ha de extrañar, por ello, que Categorias, en su búsqueda de la expresión ajustada (definidicional, delimitadora) de lo que es, acabara adentrándose por el camino marcado en Top. VII, destacando que la diferencia, aun siendo una característica del tipo de la cualidad, participa de lo substancial "puesto que también la diferencia se encuentra entre las cosas que no están en un sujeto: en efecto, pedestre y bipedo se dicen del hombre como su sujeto, pero no están en un sujeto (puesto que ni bípedo ni pedestre están en el hombre)»: Cat. 5, 3a21-25.

A partir de aquí y al igual que ocurre con las determinaciones substanciales del género, Categorías destacará también que ula definición (logos) de la diferencia se predica (kategoreitai) de lo que se dice (legetal) la diferencia; por ejemplo, si pedestre se dice de hombre, la definición de pedestre se predicará también del hombre, pues, en efecto, el hombre es pedestre" (Cat. 5, 3a25-28). De este modo, la diferencia opera definicionalmente en pie de igualdad con el género: «Pertenece a las substancias y a las diferencias que todo aquello que se di-

42 Asimilación que, como dijimos, se hace explícita en Top. IV, 2, 122b15-17 y VI, 6, 144a15-19. Esta asimilación, como ha subrayado GrANGER (Aristotle on Genus and Differentia, a. c., p. 9) se mantendrá a lo largo de la obra de Aristóteles, incluida la Metafisicar cfr. V, 14, 28, 1024b8-9; VII, 2, 1042b22; X, 9, 1058a37.

43 Dejar la definición únicamente a cargo de lo substancial (especie y género) implica que el individuo-que-es quede dicho, simplemente, por las aportaciones de la predicación de la especie y del género, en la medida en que éste, al predicarse de la especie, se predica también del individuo. Ahora bien, si la predicación que la especie hace del individuo es harto general y de poca consistencia delimitadora, más general e uin-diferenciada” es la género, destinado a poner de manifiesto lo que es común a especies delimitadas y diferenciadas entre sí. 
ce a partir de ellas sea dicho sinónimamente, pues todas las predicaciones que se hacen a partir de ellas se predican o de los individuos o de las especies. Es bien cierto que no hay predicación alguna a partir de la substancia primera (en efecto, no se dice de ningún sujeto); en cuanto a las substancias segundas, la especie se predica del individuo y el género tanto de la especie como del individuo; del mismo modo, las diferencias se predican también tanto de las especies como de los individuos. Y las substancias primeras admiten la definición tanto de las especies como de los géneros, mientras que la especie, por su parte, admite la definición del género, pues todo lo que se dice del predicado se dirá también del sujeto. Del mismo modo, las especies y los individuos admiten la definición de las diferencias. Como dijimos que eran sinónimas aquellas cosas cuyo nombre es común y cuya definición es la misma, resulta que todas aquellas cosas que se dicen a partir de las substancias y las diferencias se dicen sinónimamente» (Cat. 5, 3a33ss.).

Resulta de todo ello que, al establecer Categorias la sinonimia operativa entre género y diferencia, se está apelando y haciendo entrar en juego una más acusada proyección del logos definidor como logos de-limitador y de-terminante, toda vez que la impronta de lo genérico-común pasa a estar controlada por la carga diferenciante de lo que queda definido atendiendo también a la diferencia. De este modo, el logos presocrático que despliega la presenciación unitaria de todo lo presente cede ahora su puesto privilegiado al discurso definidicional entendido como manifestación diferenciadora de lo existente, de tal modo que la realidad queda mejor revelada y mejor entendida cuanto más definida, es decir, cuanto más delimitada y determinada en el ámbito de la definición.

En consonancia con lo anterior, Aristóteles puede verse ya justificado para establecer la característica fundante de lo substancial-definitorio en ser donación/manifestación de un "esto" (tode), lo delimitado/determinado por excelencia. El género y la diferencia no significan ya, en este caso, simplemente la substancia, sino la substancia cualificada-determinada: «determinan (aphoritsei) lo cual respecto de la substancia, puesto que significan una substancia tal o cual (poian tina ousian semainei). Se hace una determinación (ton aphorismon poieitai) mayor en el caso del género que en el de la especie, pues al hablar de animal se abarca más que al hablar de hombrem: Cat. 5, 3b20-23. Es cierto que, en el texto citado, nada se dice acerca de la diferencia, habida cuenta de que el texto en cuestión está referido a las substancias (especie-género) y la diferencia no es substancia sino característica/propiedad, aquel poion ti caracterizado como tal en Top. IV, 2, 122b15-18; VI, 6, 144a15-19. A pesar de ello, el texto citado 
de Cat., 5 resulta sorprendente en la medida en que la configuración substancial de la especie y del género queda, ahora, realizada atendiendo a la función diferenciadora-determinadora (en sí misma, característica fundamental de la diferencia) ${ }^{44}$ que exhiben las substancias segundas en cuanto expresión de un tode individualizado, delimitado, confirmando lo que ya había anunciado Cat. 5 , 2b7ss., que la especie es "más substancia" que el género porque "está más cerca" de lo individuo, de la substancia primera. Cat. 5, 3b20-23 lo que hace es explicar que aquel "estar más cerca" ha de entenderse como capacidad de cooperar a determinar/delimitar/diferenciar cuando de lo que se trata es de dar cuenta de la manifestación-revelación de la realidad y «realidad» es entendida según las exigencias del logos definidor como presenciación de las cosas diferenciadas, delimitadas, que son ${ }^{45}$.

$\mathrm{Si}$, pues, Categorias pone el acento en el logos-presenciación de las cosas que son (que es, por lo demás, inseparable del logos-palabra en que se explicita aquella presenciación) y lo hace de tal modo que el logos-presenciación acaba configurándose en su darse como delimitación y diferenciación, hay que concluir que, con este planteamiento, la filosofía aristotélica deja de estar en sintonía con las exigencias del lógos/physis presocrático como apeiron y armonía de contrarios e, incluso, del logos/physis platónico, mezcla de límite (peras) y de ilimitación (apeiron) ${ }^{46}$. Distanciándose de esta tradición y acentuando la función diferen-

44 De hecho, Categorias tratará ahora a la especie y al género como poion ti (respecto a la substancia), del mismo modo que Topicos dice de la diferencia que es poion ti. cfr. Cat. 5, 3b1516.

45 La vinculación de la diferencia, en pie de igualdad con el género, al discurso definidor acerca de lo que es lleva a Aristóteles a rechazar una teoría de la definición basada en una mera división por géneros (dia ton genon diairesis), a la que Aristóteles ve como un «silogismo sin fuerza" pues "postula lo que es preciso demostrar y concluye siempre alguno de los predicados superiores (...) (poniendo) lo más universal como medio y aquello acerca de lo cual había que hacer la demostración y las diferencias como extremos" (An. Pr. I, 31, 46a33-34; 46b20-22), por lo que no puede mostrar que lo que se investiga «sea esto o lo otro de modo necesario». La división por géneros, en efecto, no puede mostrar que el hombre es un animal mortal sino que tan sólo llega a decir que todo animal es mortal o inmortal o que todo animal mortal es pedestre o bípedo, según los ejemplos de $A n$. Pr. I, 31. Cfr., igualmente, An. Post. II, 5, 91 a27-92a5. No compartimos, sin embargo, la tesis de Robert BolToN, según la cual el texto de An. Post. II, 13 ha de ser entendido como exigencia de que todo tipo de definición por división (y no solamente la de la división por géneros) es ajeno a cualquiera de los tipos de definición científica examinados en An. Post. II, 10: vid. "Division, définition et essence dans la science aristotélicienne", en Revue philosophique de la France et de l'étranger, 2, 1993, pp. 197-221.

46 Para Platón, la coexistencia de lo peras y de lo apeiron es lo que hace posible que se produzca la presenciación de lo presente-compuesto de lo uno y lo múltiple, por lo que aquella co- 
ciadora del logos definidor, Aristóteles se ha visto conducido a acogerse a un modelo de realidad estructurada y delimitada, ajena a la coexistencia de contrarios y determinada/delimitada de modo preciso, cuantificado: "pertenece también a las substancias el que no haya nada contrario a ellas. Pues ¿qué podría ser contrario de la substancia primera? Por ejemplo, no hay nada contrario del hombre individual, ni tampoco hay nada contrario de hombre o animal. Sin embargo, esto no es algo propio de la substancia, sino de otras muchas cosas como de lo cuanto. No hay, en efecto, nada contrario de los dos codos, ni de los diez, ni de cualquier otra cosa de éstos, a no ser que alguien diga que lo mucho es contrario de lo poco o que lo grande lo es de lo pequeńo; pero nada hay que sea contrario de lo cuanto determinado (to aphorismon poson): Cat. 5, 3b24-32.

Partiendo de aquí, la filosofía aristotélica abogará por una configuración lógica y ontológica derivada de la estructura del saber y de la racionalidad definidores, vistos a la luz de unas exigencias diferenciadoras y definitivas que iban a

existencia se traduce en una auténtica genesis eis ousian y es, por ello, la configuración que determina el ser de la realidad, así como el de su ordenamiento ontológico: "Los antiguos, que valían más que nosotros y que vivían más cerca de los dioses, nos han transmitido esta tradición, que todo lo que se puede decir y existe está hecho de lo uno y de lo múltiple y contiene en sí mismo, originariamente asociados, el límite y la ilimitación (peras de apeirian)": Fil, 16c. Ello es lo que conduce a Platón a establecer su particular ontología de la Idea-Forma: "nos es, pues, necesario, puesto que las cosas están así ordenadas, poner siempre, en cualquier conjunto, y buscar, en todos y cada uno de los casos, una forma única (mian idean): Fil, 16d. La doctrina del Filebo se relaciona con aquellos otros diálogos platónicos (caso, por ejemplo, de Sof., 242css.; Parm., 127ess.; Fed, 261dss.) preocupados por dar cuenta de la multiplicidad de lo presente en función de lo uno/múltiple, limitado/ilimitado. Parm., 158c-d resulta especialmente significativo: "Aislada de este modo, la naturaleza extraña a la forma (heteran physin tou eidous), todo lo que podamos ver de ella ¿¿no será multiplicidad ilimitada (apeiron)? - Absolutamente.- Y, sin embargo, una vez que cada parte, una por una, se ha hecho parte, se ve limitar (tiene límite, peras echei) por las otras partes y por el todo y el todo tiene límite (es limitado) por las partes. - Ciertamente.- Así, los otros que son el Uno tienen comunidad con el Uno y con ellos mismos y por ello nace, al parecer, en ellos ese algo extraño que les aporta limitación (peras) recíproca. En cuanto a su naturaleza propia, no le ha dado, propiamente hablando, más que ilimitación (apeirian).- Eso parece.- Así, los otros que no son el Uno, ya se les considere como todos o como partes, son ilimitados (apeira) y participantes del límite (peratos echei)".- - Perfectamente». Mientras que, para la tradición presocrática, lo apeiran es la presencia misma (ser, logos, physis, arche), Platón llega a la conclusión de que lo apeiron es la diversidad individual de lo presente, lo opuesto a la unidad del género-Uno-Ser, la multiplicidad confusa que exige remitirnos a la Forma-Idea única (lo peras). Aristóteles se servirá de este distinción, pero haciendo de lo peras (el límite, lo definidor) un elemento perteneciente, por sí mismo, a la presenciación de las cosas, sin necesidad, por tanto, de acudir al mundo platónico de las Ideas (aquel «algo extraño» a las cosas, al que se había referido el Platón del Parménides). 
enmarcar el desarrollo de la cultura y de la historia del pensamiento occidentales, una vez que el Occidente medieval asimiló el pensamiento del estagirita, haciéndose deudor de él. Aquellas exigencias, surgidas al amparo de la atención prestada por Categorias al componente ontológico del discurso humano ${ }^{47}$ iban a encontrar su caracterización cumplida en $A n$. Post. y, sobre todo, en la Metafisica $^{48}$, la obra en que se compendia de modo más acabado la vertiente ontológica de la filosofía aristotélica. Lo que hemos de mostrar ahora es que, mientras que Aristóteles se atiene al plano del logos-discurso, el género es el elemento

47 Dejemos para otra ocasión examinar la cuestión de hasta qué punto el origen de la configuración diferenciadora y alusiva a la definitividad que caracteriza al logos definidor aristotélico fue una consecuencia de la consolidación de los conocimientos científico-biológicos de un Aristóteles preocupado por dar cuerpo a un saber que fuera capaz de explicitar un mundo estructurado ordenadamente, lo que llevó a Aristóteles a elaborar su doctrina acerca de la ciencia a partir de un discurso y de una racionalidad definidores-diferenciadores. Para hacerse una opinión en este punto, pueden consultarse BALME, O. M., "Genos and Eidos in Aristotle's Biology", en The Classical Quarterly, 12, 1962, pp. 81-98, así como los trabajos del mismo Balme recogidos en Gotthelf, A., y Lennox, J. G., eds., Philosophical Issues in Aristotle's Biology (Cambridge, Cambridge University Press, 1987), pp. 9-20; 69-89; 291; 312; LloYD, G. E. R., "The Development of Aristotle's Theory of Classification of Animals", en Phronesis, 6, 1961, pp. 59-81; Grene, M., Is Genus to Species as Matter to Form?, a. c., pp. 55ss. Por nuestra parte, nos limitaremos a señalar que la búsqueda de una adecuada clasificación biológica no llevó a Aristóteles a un tratamiento sistemático del área de lo biológico en función de géneros y especies. Así, la $H i s-$ toria animalium se centra fundamentalmente en descubrir las diferencias como motor del proceso definidor de las diferentes especies animales, como ha destacado Balme en sus trabajos citados en esta misma nota y, también, McKirahan, R. D., Principles and Proofs. Aristotle's Theory of Demonstrative Science (Princeton, N. J., Princeton University Press, 1992), p. 236. Ello no impide que, a nuestro juicio, Aristóteles siguiera manteniendo que una caracterización sistemática de la biologia habría necesitado acudir a la definición a través del género y de la diferencia, tal como exige Met. I, 8, refiriéndose precisamente a las clasificaciones biológicas.

48 La Metafisica aristotélica se ocupa de la definición en, fundamentalmente, los capítulos 4-6 y 10-12 del libro VII y en los capítulos 3 y 6 del libro VIII. De estos textos, el más significativo es el de VII, 12, y no sólo por la relación que guarda con los planteamientos que Tópicos y An. Post. II, 13 hacen de lo concerniente a la definición. En relación con ello, señalemos que $M e t$. VII, 12 es posterior a la redacción de $A n$. Post. II, 13, como ha sido establecido por LLoyd, el cual también ha señalado que Met. VII, 12 es anterior al De partibus animalium I, 2-4, donde se encuentran (junto con las secciones introductorias de la Historia animalium) las líneas maestras de la filosofía de la biología aristotélica y donde Aristóteles apunta (sin llegar a establecer una teoría sistemática) a un tipo de definición por división más complicada que la definición/división dicotómica de la lógica y de la metafísica aristotélicas: cfr. $P A 1,2-3,64 \mathrm{~b} 21$ ss. A pesar de ello, lo apuntado en De partibus no ha de verse, creemos, como modificación substancial de lo que establecen para la definición Met. VII, 12 y An. Post. II, 13. Para una opinión contraria, vid. McKirahan, R. D., Principles and Proofs. Aristotle's Theory of Demonstrative Science, op. cit., pp. 115 ss. 
preeminente de la definición ${ }^{49}$ y que cuando, por el contrario, Aristóteles pasa a subrayar la orientación ontológica de aquel logos-discurso, es la diferencia la que ocupa el lugar fundante de lo revelado en la definición.

\section{La ontología diferenciadora de la definición aristotélica}

En la Metafisica, aparece ya claramente consolidada la convicción aristotélica de que la presenciación de lo que es (en su máxima generalidad, el ser) sólo es posible en el desvelamiento (a) de las cosas que son, y (b) en tanto de-terminadas, de-limitadas, $y$, por consiguiente, de-finidas. La realidad, el mundo, es vista, en este caso, a través de un Aristóteles-metafísico, dispuesto ahora a revelar la profundidad de lo racional del discurso del Aristóteles-científico que tan buenos dividendos había encontrado en su clasificación de la parcela mundano-biológica. Puestas así las cosas, la Metafisica aristotélica es deudora de un supuesto operativo concreto, el de que la realidad es lo que puede y debe darse como lo primariamente ordenado, siendo este ordenamiento primario la manifestación originaria de las cosas mundanas. La autenticidad del saber reside, en este caso, no en un saber de las cosas que simplemente son, sino en un saber de las cosas en tanto que realidades substanciales de-limitables y di-ferenciables de modo definitivo entre sí, en la línea de lo que había sido anticipado en Categorias.

La donación de-limitadora del ser se hace, pues, de-finición en cuanto diferenciación acabada (definitiva) de las substancias determinadas en que se hacen presentes los seres a través del proceso del logos definidor, el cual encuentra, así, su cumplimiento acabado (su per-fección) cuando la definición llega a la imposibilidad de establecer ulteriores diferenciaciones puesto que, en este caso, se ha llegado a la "predicación última" que revela la ousia concreta (An. Post. II, 13, 96b11-13). Alcanzado este paso, puede ya decirse con propiedad que el logos definidor es el "logos único que es la definición de la cosa concreta" (An. Post. II, 13, 97b12-13), el logos que ha des-velado la entidad substancial, el que ha puesto de manifiesto lo to ti en einai del referente real concreto de una expre-

49 Así, Met. V, 26-28 seguirá advirtiendo que, en el orden de lo conceptual y de lo discursivo, el género es el elemento primero de la definición, aquello de lo que se dice en que consiste la esencia (ho legetai en to ti esti) y, por ello, el sujeto-fundamento (bypokeimenon) del que se predican las cualidades (poietai), vistas, en este caso, como diferencias (diaphorai) del género: Met. V, 28, 1024b1ss. 
sión definidora determinada. De ahí que la doctrina de la definición de la $M e-$ tafisica aristotélica explicite lo que ya había sido anunciado en los Analiticos y haga de la manifestación de lo real un progresivo desvelamiento de diferencias, a partir de unas diferencias previamente adquiridas, hasta llegar a la diferencia última, realización por antonomasia del logos definidor. Por todo ello, en la puesta en práctica del discurso definidor ya no será el género, sino la diferencia, el elemento que cobre el mayor protagonismo, estableciendo Met. VII, 7, 1031al1-12; 1032b1-2 que es la diferencia el ámbito propio de la definición justamente por ser la diferencia la revelación primaria de lo substancial y también Met. VII, 12, 1038a19-20 insistirá en ello: «resulta evidente que la diferencia última será la substancia del sujeto concreto y su definición (teleutaia diaphora he ousia tou pragmatos estai kai ho horismos)" 50 .

En relación con lo que se acaba de decir hay que tener presente que la visión de la definición que ofrece Met. VII, 12 contribuye en no pequeña medida a clarificar lo que Analíticos había propuesto acerca de la división. En $A n$. Pr., I, 31, 46a31ss. se advierte, en efecto, que la división por géneros (dia ton genon diairesis), al tomar lo más universal como término medio, no puede concluir (demostrar) ni la ousia ni el ti esti. De una división tal, que se limita al plano de la disyunción (el animal es pedestre o no-pedestre; racional o no-racional), «no resulta en modo alguno necesario que exista tal cosa determinada (to pragma ekeino) al existir estas otras" (An. Post. II, 5, 91b14-15).

Tampoco soluciona demasiado afirmar que la definición es el conjunto de lo que se ha propuesto disyuntivamente porque una afirmación tal no resulta ser «algo necesario a partir de lo que se ha dicho, sino que también esto se acepta sin más" (ibid., 91b20-21) pues se trataría de un conjunto que, aun siendo verdadero de una especie dada, no mostraría ni lo ti esti ni lo to ti en einai (ibid., 91b25). Por el contrario, An. Post., II, 13 (un texto probablemente redactado con posterioridad a An. Post. II, 5) pondrá de manifiesto cómo la división puede estar estar relacionada con los elemenos referidos a lo ti esti51, anticipando lo que Met. VII, 12 dice acerca de la definición por división. Para ello, An. Post. II, 13 va a centrarse ahora en las divisiones por diferencias (diaireseis kata tas diaphoras), cuya utilidad resulta ser clara a Aristóteles para demostrar la esencia

so Cfr., igualmente, Met. VII, 12, 1038a29-30: "La definición es el logos que procede de las diferencias y, en rigor, de la última de ellas».

51 Para una interpretación diferente de la aquí apuntada, vid. Bolton, R., Division, definition et essence dans la science aristotelicienne, a. c., pp. 201 ss. 
(syllogitsesthai to ti estin) con tal de que, acogiéndonos a la diferencia apropiada, la división sea manifestación del predicado/diferencia última "pues es evidente que si, procediendo así, se llegara a aquellas cosas de las que ya no existe diferencia, se tendría el enunciado de la substancia (exei ton logon tes ousias): $A n$. Post., II, 14, 97a18-19.

La división por diferencias ofrece, pues, la definición como de-limitación de la ousia de lo así definido, siempre que "el hablar-definidor por divisiones» (horon dia ton diaireseon) cumpla tres requisitos básicos: (a) que el logos-palabra definidor opere con predicados esenciales (kategoroumena en to ti esti), con vistas (b) a ordenarlos (taxai) según un primero y un segundo (An. Post. II, 13, 97a2326) y que (c) los predicados asi divididos-ordenados sean todos de tal modo que "del último todo ya no hay diferencia" (ibid., 97a38), con lo que se llegará a aquel enunciado único (ena logon) que es la definición de la esencia de la cosa determinada (ibid., 97b13), la definción que revela el atomon eidos.

Las significativas variantes introducidas por An. Post. II, 13 en el conjunto de la lógica aristotélica son el resultado de volver a poner en un primer plano el subsuelo ontológico del logos-discurso. Mientras Aristóteles se mantiene en el ámbito del logos-discurso, sin más, la división resulta inadecuada e insuficiente para la construcción del edificio silogístico-dialéctico pues la definición (horismos) no se hace silogismo (An. Post., II, 5, 92a5). Si se trata, por el contrario, de explicitar que el discurso-por-división (las expresiones-divisorias: diairetikoi horoi) son inseparables de un calado y de una proyección ontológicas de tal manera que el orden (taxis) del logos-palabra divisor lleva al ordenamiento de la realidad desde la perspectiva de lo esencial hasta alcanzar lo substancial (en lo que ya no hay posibilidad efectiva de un orden ulterior), aquellas diairetikoi horoi revelarán, entonces, su capacidad de ser auténtica definición (horismos), es decir, logos que manifiesta el orden de-limitado, di-ferenciado de las cosas que son y que, con ello, explicita la racionalidad (logos) del mundo definido, al que tanto An. Post. II, 13 como Met.. VII, 12 apuntan en sus consideraciones.

\section{El alcance de la definición}

De acuerdo con lo dicho, la ontología aristotélica es deudora de la tesis de que la definición como división por diferencias «es la única manera de no dejar nada de lado en lo ti estin (An. Post. II, 13, 96b35-36). Entendida, así, la definición como diferenciación progresiva de diferencias previas, el logos-definidor será un 
"dividir por la diferencia de la diferencia" (Met. VII, 12, 1038a9-10) y un revelar las diferencias: horismos estin o ek ton diaphoron logos (Met. VII, 12, 1038b8-9). $\mathrm{Al}$ ser la diferencia el elemento en que primariamente se apoya el logos-definidor que manifiesta el logos-physis de la presenciación de lo real, resulta que lo real-presenciado (las cosas) será justamente lo diferenciado y el logos/eidos de las cosas reales-diferenciadas ya no podrá ser el in-definido/in-diferenciado eidos genérico de Platón (la mia idea del Filebo) sino que, por el contrario, «habrá tantos eidos cuantas sean las diferencias", de tal modo que si, acogiéndonos al ejemplo aristotélico, el logos definidor ha llegado a la revelación/diferenciación de "animal" en "animal provisto de pies", es posible establecer, a partir de aquí, unas diferenciaciones ulteriores (v.gr., cisípedos/solípedos) hasta poder decir que «los animales provistos de pies serán tantos como las diferencias»: Met. VII, 12, 1038a9-19.

Este resultado es inseparable de la constitución procesual del discurso definidor ${ }^{52}$, que ha de conducir a la diferencia-sin más-diferencias (a la diferencia

52 Cuestión aparte es la de cómo se produce esta constitución del logos definidor, un tema que nos llevaría a los complejos tratamientos del De anima acerca de la función del entendimiento (agente y paciente) en relación con los datos de la sensación. En cualquier caso, séanos permitido señalar que, para Aristóteles, es en la propia sensación (en las sensaciones persistentes) donde se da la intuición de la esencia y de lo universal, un planteamiento del que pocas veces se ha hecho notar su afinidad con la intuición fenomenólogica de esencias, intuición de la que acertadamente dijo Merleau-Ponty que no encerraba más misterio que la sensación misma. Ahora bien y volviendo a Aristóteles, éste indica expresamente que la esencia/universal «surge» (ginetal) justamente en la medida en que, en la persistencia de las sensaciones, surge ya una diferencia (ede diaphora ginetai) que es logos, identificando así la aparición de la diferencia y la de la definición: vid. An. Post. II, 19, 100a1-6 (cfr. el paralelismo existente este texto de Analíticos y el de Met. I, 1, 980b28-981a1). En lo conocido sensiblemente (en lo indiferenciado) se da paso, entonces, a la diferencia-definición y, con ella, a ulo universal en el alma puesto que, al conocer sensiblemente lo singular, la sensación es de lo universal (he d'aisthesis tou katholou estin): An. Post. II, 19, 1000a15-17. En la génesis de la definición, Aristóteles apunta, por ello, a una inmediatez que hace imposible que se dé episteme de la definición (es decir, episteme "por la que podamos ser conscientes de las definiciones»), del mismo modo que, según An. Post. II, 19) no hay episte$m e$ de los principios inmediatos de la demostración. Esta afirmación última parece contradecir el supuesto de An. Post. II, 3, 72b19-24 y de An. Post. II, 33, 88b34-38 de que debe existir episteme de los primeros principios, una contradicción que BYRNE (Analysis and Science in Aristotle, op. cit., pp. 170-189) cree poder resolver acudiendo a los diferentes significados que Aristóteles otorga a episteme y a nous, aunque la cuestión aquí señalada encierra no poco complejos vericuetos que afectan a la obra en general de Aristóteles: vid. McKirahan, R. D., Principles and Proofs, op. cit., pp. 237-271; FEREJOHN, M., The Origins of Aristotelian Science (New Haven/London, Yale University Press, 1991), pp. 38-61; Hesz, W., "Erfahrung und Intuition bei Aristoteles", en Phronesis, 5, 1970, pp. 48-81; KAL, V., On Intuition and Discoursive Reasoning in Aristotle (Leiden, Briel, 1988). 
última), es decir, a la unidad de lo substancial, incapaz ya de ulteriores diferenciaciones. Ello es así desde el momento en que, en la concepción que de la definición tiene la Metafisica aristotélica, la presenciación de cada paso diferenciador supone la adquisición de un logos que manifiesta una realidad más delimitada y ordenada que la anterior, la cual, a su vez, se presta a una más profunda delimitación y ordenación diferenciadas hasta que pueda decirse razonadamente que se ha llegado a la diferencia última, manifestación del eidos visto como donación de lo substancial de las cosas que son 53 . En este caso, puesta la substancia en función de la diferencia última, sin capacidad de ulteriores diferenciaciones ordenadoras, la substancia es lo uno, el atomon eidos, lo determinado/delimitado por excelencia: ousia en ti kai todo ti: (Met. VII, 12, 1037b27). De este modo, la meta de la definición coincide con la de la filosofía, alcanzar la unidad de lo substancial, que es la unidad que ya no puede servir de base/género a nuevas diferenciaciones y ordenaciones, tal como resume la concisa, pero magistral, fórmula de Met. VII, 12, 1038a33: «En la substancia no hay orden (taxis d'ouk estin en te ousia)" 54 .

53 Puede, entonces, pensarse que la investigación filosófica es inseparable de aquel limite ideal que permita "decir razonadamente" que se ha alcanzado la donación de la realidad misma. La cuestión fundamental pasa a ser, en este caso, cómo pueda de-limitarse legítimamente aquel "decir razonadamente" o, dicho más directamente (al estilo de las reflexiones que la doctrina peirceana de la verdad ha suscitado en el último Rorty), la de si tiene sentido establecer la posibilidad de un final de la investigación, que se consumaría en la revelación de la realidad-sin másdiferenciaciones. Pero así como los peirceanos no ven en las objecciones del tipo de las de Rorty más que una mala interpretación de la doctrina del fundador del pragmatismo, tampoco los aristotélicos considerarían bien encaminadas las interpretaciones que confunden aquel "decir razonadamente" con el límite ideal de la investigación. Para Aristóteles, en efecto, "decir razonadamenten es exhibir el logos definidor, el cual revela de modo necesario la ousia en la diferencia (específica) última que se alcanza, de hecho, a través de una adecuada aplicación de la división, en cuyo caso ya no es posible pensar que pudiera darse alguna diferencia específica ulterior, ya que tendría que ser o género o diferencia, algo que, en cualquiera de los dos casos, resulta incompatible con el concepto de «diferencia última» (cfr. An. Post. II, 13, 97a23-b6). Claro está que con este tipo de argumentación (anticipatorio de la tan vapuleada prueba anselmiana) Aristóteles deja sin responder la objección básica a la que aquí estamos aludiendo, ya que el método aristotélico no puede aportar justificación adecuada para que se pueda decir con propiedad ("razonadamenten) si y cuándo se ha llegado a aquel enunciado único (eis ena elthe logon) que sería la definición de la cosa en cuestión (tou pragmatos horismos), a la que se refiere An. Post. II, 13, 97b12-13.

54 Siendo, en efecto, lo substancial lo contenido en el logos-definición última, la substancia es incompatible con la posibilidad de ulteriores delimitaciones porque lo uno ya no admite la determinación de lo anterior y de lo posterior (Met. VII, 12, 1038b33-34) una vez que el proceso diferenciador ha alcanzado ya el atomon eidos en que se concreta la definición acabada (vid. nota anterior sobre la dificultad que tiene la metafísica aristotélica para poder decidir justifica- 
Como resultado de todo ello, en la substancia-sin-orden se concreta la definitividad de lo mostrado en la definición y, en general, la definitividad (apuntada ya en Categorias) del logos que significa la esencia de las cosas que se dan. Lo no-substancial (lo accidental) es, así, lo in-substancial, lo incapaz de de-limitación/de-finición última: «si se atiende a lo accidental, si se divide, por ejemplo, en los animales provistos de pies lo blanco y lo negro, las diferencias serán tantas como los cortes de la división” 55. Lo accidental es, por ello, incapaz de ordenar/definir la realidad y ha de quedar fuera de los límites que enmarcan la manifestación de lo esencial y carece, por consiguiente, de auténtica significación, es estrictamente in-significante, desde el momento en que no tiene una vinculación característica con la diferencia, base de la definición ${ }^{56}$.

Alguien podría decir que, a pesar de todo y de acuerdo con el propio Aristóteles, lo accidental (las categorías que no son substancia) da pie a la constitución de una cierta unidad, la que aparece (según el ejemplo de Met. VII, 12) en "hombre blanco". Ahora bien, se trata, en estos casos, de la unidad accidental que pone de manifiesto un ordenamiento que no está referido a la esencia misma del sujeto y que, por ello, es incapaz de generar una auténtica progresión en la diferenciación/delimitación del sujeto ya que siempre será posible establecer in-definidamente nuevos "cortes" (accidentales), teniendo siempre en cuenta que "las diferencias serán tantas como cortes en la división". A la unidad de lo substancial, a la que apunta la definición, se llega, por el contrario, a través de sucesivas diferenciaciones que tienen un límite (ideal, al menos) consistente en la manifestación de la substancia-sin-orden, la substancia una que se manifiesta en la diferencia última.

Los sucesivos pasos de esta "definición según las divisiones» consolidarán la especial relación existente entre el logos-definidor y la diferencia, por más que

damente si aquella definición acabada ha sido alcanzada). La diferencia sustenta, así, el alcance ontológico de la definición ya que las cosas que son distintas meramente en cuanto al género (betera to genei) "no se resuelven (analyetai) ni unas en otras ni en algo único (eis allela oute eis en ti): Met. V, 28, 1024b15-16.

55 Cfr. Met. VII, 12, 1038a26-28. La definición por división, a la que se acoge el ARISTOTELES de Met. VII, 12, en la medida en que conduce a la donación de la unicidad de lo substancial se opone a la división por accidentes, la cual lleva a una pluralidad de especies en función de las diferentes divisiones establecidas y que es, por ello, ajena a la revelación de la substancia-uno.

56 Cfr. Top. VI, 144a24-26: "Ninguna diferencia es de las cosas que se dan por accidente, como tampoco el género, pues no es posible que la diferencia se dé y no se dé en algow. 
siga siendo necesaria la presencia del género ${ }^{57}$, visto por Aristóteles como la materia in-determinada 58 a partir de la cual se hace posible el operar de-terminador ${ }^{59}$, de-limitador y de-finidor (la diferencia). La función diferenciadora del

57 «No hay otra cosa en la división fuera del llamado género primero (proton genos) y las diferencias. Los demás géneros son el primero junto con las diferencias afiadidas a él»: Met. VII, 12, 1037b29-31. De ahí que, aun en el caso más simple de la definición por división, se necesitan dos términos, de los cuales necesariamente «uno será diferencia y el otro, género" (Met. VII, 12, 1038a4). En cualquier caso, no conviene perder de vista el aviso de Donald Morrison acerca de la precaución con que hay que tomar Met. VII, 12 como defensa paladina de la homocategorialiedad de la diferencia con la especie y la esencia: cfr. Le statut catégoriel des differénces dans l'Organon', a. c., pp. 174-176.

58 Para la identificación entre género y materia, cfr., especialmente, Met. V, 28, 1024a2969; VII, 7, 1. 033a3ss.; VII, 12, 1038a5-9; VIII, 3, 1043b28-32; VIII, 6, 1045a14-36; X, 3, 1054b27-31; X,3 1057b37-1058a26. A partir de aquí, autores como Balme, Lloyd y, sobre todo, Rorty han sostenido que, en la definición, el género expresa la materia real y física de las substancias y organismos compuestos: vid. RORTY, R., "Matter as Goo: Comments on Grene's Paper", en Synthese, 28, 1974, pp. 71-77; "Genus as Matter: A Reading of Metaphysics Z-H", en RORTY, R.; LeE, E. N., y Mourelatos, A. P. O., eds., Exegesis and Argument: Essays on Greek Philosopby Presented to Gregory Vlastos (Assen, Van Gorcum, 1973), pp. 393-420. Esta tesis ha sido combatida por GrENE, M., "Is Genus to Species as Matter to Form? Aristotle and Taxonomy", en Synthese, 28, 1974, pp. 51-69, en una, a nuestro juicio, más convincente línea, según la cual los textos aristotélicos sólo permiren concluir que el género funciona en la definición al modo como la hace la materia de los individuos compuestos, es decir, como elemento que muestra las potencialidades o alternativas que han de ser determinadas por la diferencia/forma. El tema, con ello, no queda resuelto, habida cuenta de las dificultades que encierra la caracterización lógica y metafísica de la diferencia como forma, un tema que está en dependencia del uso plural que Aristóteles hace de "forma", acerca de lo cual puede verse GARAY, J. de, Los sentidos de la forma en Aristóteles (Pamplona, Eunsa, 1987). A pesar de ello, conviene aquí destacar que Aristóteles, al afrontar el alcance ontológico de la definición, hizo explícita identificación entre la forma, la substancia y la diferencia (en la medida en que en esta última encuentra consistencia la definición como revelación de lo uno-determinado): cfr., por ejemplo, Met. V, 9, 1017b23-26: «La esencia (to ti en einai), cuyo enunciado es definición (ou ho logos horismos), ella también se llama substancia (ousia) de cada cosa. Resulta, pues, que la substancia se dice en dos sentidos: el sujeto último que ya no se predica (legetai) de otro y, lo que siendo algo determinado (tode tion), es también separable. Y esto es la forma (morphe) y la especie (eidos) de cada cosa». Si, desde una perspectiva ontológica, la definición consiste en la diferencia, hay que tener en cuenta que lo formulado en la definición (logos) es la forma o especie (morpheleidos. cfr. Phys. II, 1, 193bl-2) o la esencia (Phys. II, 7, 198a15-33). Del mismo modo, Phys. II, 1, 194a21-b10 insistirá repetidamente en que la forma es lo to ti en einai, dicho sea esto sin que olvidemos que, en De anima I, 1, 403a30-68, Aristóteles parezca inclinarse por una más estricta distinción entre materia y forma y que, en este caso, lo to ti estin y lo to ti en einai englobarian tanto la materia como la forma.

59 En la década de los cincuenta, una significativa parcela de los filósofos analíticos (caso de, entre otros, PRIOR, JOHNSON, KORNER o SEARLE) prestaron especial atención a los problemas lógicos suscitados por la relación entre lo determinable-determinado-determinante, problemas 
logos definidor no opera, en efecto, en el vacío sino a partir de las potencialidades suministradas por el género, al que la diferencia de-limita y de-termina. El género es, en definitiva, necesario en la definición en la medida en que hace posible la actualización diferenciadora, el "logos basado en las diferencias". En la diferencia se hace presente la definición y, en ella, el género delimitado por la diferencia, por lo que, en última instancia, teniendo la diferencia, ya no se hace preciso mencionar al género, por más que la diferencia sólo pueda hacerse operativa a partir del género. La definición revela, en efecto, el eidos y, con él, el género, que no existe fuera de las especies consideradas como pertenecientes a él 60 .

En un planteamiento de este tipo acerca de la definición, el género no participa de las diferencias porque, en este caso y al revés de lo que sucede en la división accidental, el género «estaría participando al mismo tiempo de los contrarios, ya que las diferencias por las que se diferencia el género son contrarias" (Met. VII, 12, 1037b20-21). A su vez, tampoco las diferencias pueden participar del género como si fuera un sujeto puesto que, entonces, las diferenciascontrarias participarían de lo común (género) y, en definitiva, "de todas las cosas resultaría una solam (ex apanton estai en): Met. VII, 12, 1037b2461.

Si lo que hemos venido diciendo puede considerarse una aceptable exposición de la configuración lógica y ontológica de la doctrina aristotélica de la definción, habrá que concluir que aquella doctrina hace que la filosofía del estagirita se aleje decididamente de la senda marcada por el origen y el discurrir que, hasta este momento, había seguido el pensar filosófico. La filosofía presocrática se constituyó como razón que intentaba dar cuenta de que el logos/phy-

que mostraban facetas que no podían equipararse a los que creyó dar solución Aristóteles en su caracterización de lo determinable-género y de lo determinante-diferencia. Para lo aquí apuntado, vid los trabajos aparecidos en los Proceedings of the Aristotelian Society, 33, supp. vol., 1959.

60 Claro está que, en un sentido estricto, ello habría de estar referido al plano lógico, de acuerdo con Top. II, 109b4-7: «de ningún género se dice parónimamente la predicación (paronymos he kategoria legetai) según la especie (eidos), sino que todos los géneros se predican (kategoreitai) sinónimamente de las especies, pues las especies admiten (epidechetai) tanto el nombre como el enunciado (logos) de los géneros». Del mismo modo, Top. IV, 120b20: "El género se predica de todas las cosas que caen bajo una misma especien. Desde esta perspectiva lógica, Top. IV, 121a5-6 podrá afirmar que ues preciso que el género quede en la misma división que la especie».

61 Acerca de las dificultades inherentes a lo aquí propuesto por Aristóteles, vid GiLl, M. L., Aristotle on Substance. The Paradox of Unity (Princeton, N. J., Princeton University Press, 1989), pp. 13-45; 111-145. 
sis, siendo único y común, era justamente armónica participación indiferenciada de contrarios ${ }^{62}$, unidad de lo que tiende a separarse y a diferenciarse (Heráclito: DK 22 B 8). Caracterizado de este modo, el logos filosófico había de convertirse en manifestación de lo "entero", de las cosas en conjunto (syllapsies), revelación de aquella "armonía invisible" que anula la consistencia de la diferencia y que, por el contrario, hace que lo diferenciado sea concordancia (diapheromenon eauto xympheretai: DK 22 B 51). A través de un lento caminar, el discurrir histórico de la filosofía llega, con Aristóteles, a una tesitura contraria, la consistente en establecer lo racional de la filosofía en un logos definidor para el que sólo tiene significado auténtico la unidad de lo de-limitado en la substancia-sin-orden, definida por la diferencia. En la unidad diferenciada de lo substancial reside la única caracterización posible que pueda darse de la unidad del logos definidor y, con él, de la filosofía misma ${ }^{63}$. Hasta qué punto esta configuración de lo filosófico dio cuerpo a la cultura occidental y a lo que ha venido siendo, hasta nuestros días, la historia de la filosofía ha de ser objeto de análisis detallados que no tienen aquí cabida. Somos de la opinión de que estos análisis pondrían de manifiesto las sucesivas presenciaciones y modulaciones de la racionalidad definidora-diferenciadora que la historia del acontecer filosófico ha ido creando a lo largo de los tiempos, acabando por convertir a esta racionalidad en el supuesto operativo básico del pensamiento occidental, supuesto que todavía sigue estando más vivo ${ }^{64}$ de lo que pudiera superficialmente creerse.

62 Mientras que el espectro lógico y ontológico de la definición aristotélica es deudor del principio de que "es imposible que los contrarios se den a la vez en la misma cosan: Top. II, 7 , $113 \mathrm{a} 23-24$.

63 "Es preciso que constituyan algo uno todas las cosas en la definición, pues la definición es un logos único (logos tis eis) y de una substancia, por lo que ha de ser logos de algo único pues la substancia manifiesta un único y un determinado (en ti kai todo ti) ": Met. VII, 12, 1037b2427. Y, como ya había avisado Top. II, 10910, "la definición no se da en ninguna otra cosa".

64 Al fin y al cabo, como ha dicho SEARLE (Determinables and the Notion of Resemblance, $a$. c., p. 142), los filósofos siguen pensando y uestán siempre diciendo que la diferencia es racionalidadw. Ello también ha sido destacado en nuestros días, aunque desde una perspectiva ajena a nuestro trabajo, por los defensores de una visión sistémica de la ciencia que propugna, al contrario de lo pretendido por la clásica racionalidad definidora-diferenciadora, una percepción del mundo desde los intereses de una globalidad interrelacionadora. Acerca de ello, puede verse el reciente y apasionado escrito de L. FERRER, Del paradigma mecanicista al paradigma sistémico (Valencia, Ajuntament-Universitat de València, 1997). 